Título: Inovação em pequenas e médias empresas: uma comparação entre Brasil e países europeus selecionados

Marcelo Duarte Silva ${ }^{1}$

Marisa dos Reis Azevedo Botelho ${ }^{2}$

Resumo: A diversidade dos sistemas de inovação, que realça a importância dos seus condicionantes históricos e sua natureza path dependent, têm sido analisada sob diferentes aspectos. A partir dessa referência mais geral, o objetivo do artigo é o de investigar as diferenças na atividade inovativa de pequenas e médias empresas, por países. São analisados indicadores da atividade inovativa entre diferentes portes de empresas para Brasil e países europeus selecionados, considerando-se os resultados, expressos na taxa de inovação, além de indicadores de gastos com atividades inovativas, cooperação e apoio do governo. Assume-se a hipótese de que essas diferenças, ademais de serem estruturais com relação ao porte, relacionam-se também às características dos respectivos sistemas de inovação. São analisados dois períodos, 2006-2008 e 2009-11, com o objetivo de verificar os impactos da crise internacional, especialmente sobre o financiamento à inovação. Fez-se uso das bases de dados da Pesquisa de Inovação Tecnológica (PINTEC), para o Brasil, e da Community Innovation Survey (CIS), para países europeus.

Palavras chave: Pequenas e médias empresas; Sistemas de inovação; Brasil; Europa.

\begin{abstract}
The diversity of innovation systems, which highlights the importance of their historical conditioning and their path dependent nature, has been analyzed under different aspects. From this general reference, the objective of the paper is to investigate the differences in the innovative activity of small- and medium-sized firms, by country. Indicators of the innovative activity between different sizes of firms for Brazil and selected European countries are analyzed, considering the results, expressed in the rate of innovation, as well as indicators of spending on innovative activities, cooperation and government support. It is assumed that these differences, in addition to being structural in relation to size, are also related to the characteristics of the respective innovation systems. Two periods, 2006-2008 and 2009-11, are analyzed in order to verify the impacts of the international crisis, especially on financing for innovation. We use the databases of the Research for Technological Innovation (PINTEC) for Brazil and the Community Innovation Survey (CIS) for European countries.
\end{abstract}

Key words: Small and medium sized firms; Innovation systems; Brazil; Europe.

Códigos JEL: L25; O30; O57.

\footnotetext{
${ }^{1}$ Mestre em Economia pela Universidade Federal de Uberlândia. E-mail: marcelods_@ hotmail.com

${ }^{2}$ Doutora em Economia pela Universidade de Campinas. Professora Titular do Instituto de Economia da Universidade Federal de Uberlândia. E-mail: botelhomr@ufu.br
} 


\section{Inovação em pequenas e médias empresas: uma comparação entre Brasil e países europeus selecionados}

\section{Introdução}

A discussão sobre como empresas de pequeno porte inovam, e se os resultados alcançados são melhores, ou mais eficientes, que os de grandes empresas tem sido alvo de intenso debate. Essa discussão pode ser resgatada desde os escritos de Schumpeter, e da clássica divisão entre a primeira e a segunda fase da trajetória intelectual do autor. Inicialmente Schumpeter propõe um papel central ao empreendedorismo individual como o motor das inovações e da mudança criativa, conhecido como Marco I de Schumpeter. Em um segundo momento, a análise do autor dá maior importância aos processos rotineiros de laboratórios de pesquisa e desenvolvimento (P\&D) em grandes empresas como a maior fonte de inovação, denominado de Schumpeter Marco II.

A literatura denominada neoschumpeteriana evoluiu significativamente nas últimas décadas, e, dentre outras, a abordagem de sistemas de inovação tem se destacado em estudos acadêmicos e política públicas. Em uma de suas vertentes, o referencial de sistemas nacionais de inovação (SNIs) destaca a grande heterogeneidade encontrada, mesmo em países com níveis de desenvolvimento socioeconômico muito semelhantes (LUNDVALL, 1992). Essa diversidade realça a importância dos condicionantes históricos para a conformação dos sistemas nacionais e sua natureza path dependent.

A investigação dessa heterogeneidade e de suas raízes tem direcionado grande parte dos trabalhos que partem desse referencial analítico. O objetivo deste artigo é o de somar-se à esse esforço, investigando as diferenças na atividade inovativa segundo o porte empresarial. Considera-se a proposição de Acs e Audretsch (1990), de que não faz sentido investigar a ocorrência dos regimes Schumpeter Marco I ou Schumpeter Marco II, pois a atividade inovativa difere de acordo com o porte da firma. Para investigar essas diferenças em nível de porte e países, foram sistematizados dados sobre a atividade inovativa de pequenas, médias e grandes empresas, para o Brasil e países europeus selecionados. A ênfase da análise recai sobre as pequenas e médias empresas e utiliza-se os dados sobre as grandes empresas, com a finalidade de comparar e identificar diferenças entre os resultados para os diferentes portes de empresas. São analisados dois períodos: 2006-2008 e 2009-11, com o objetivo de verificar os impactos da crise internacional, especialmente sobre o financiamento à inovação.

A partir dessa sistematização pretende-se avançar no entendimento das diferenças da atividade inovativa entre diferentes portes de empresas e países, considerando-se as seguintes variáveis: taxa de inovação, gastos com atividades inovativas, cooperação e apoio do governo. Assume-se a hipótese de que essas diferenças, ademais de serem estruturais com relação ao porte, relacionam-se também às características dos respectivos sistemas de inovação. Sendo assim este artigo busca contribuir para a discussão de inovação em pequenas e médias empresas no Brasil ao comparar os resultados com países europeus, bem como sugerir se há diversidades ou especificidades que diferenciem o Brasil, seguindo um enfoque de sistemas nacionais de inovação.

Para cumprir esse objetivo, o artigo estrutura-se em duas seções, além da Introdução e Considerações Finais. A seção 2 apresenta o referencial teórico, destacando os fatores determinantes para inovação em empresas de pequeno porte, sob o ponto de vista do financiamento, do apoio do governo e políticas públicas e das atividades cooperativas. A seção 3, que contém o núcleo principal do artigo, também está estruturada em subseções, que apresentam os resultados da pesquisa, obtidos a partir das bases da Pesquisa de Inovação Tecnológica (PINTEC), para o Brasil, e da Community Innovation Survey (CIS), para países europeus selecionados.

\section{Fatores determinantes para inovação em pequenas e médias empresas}

\subsection{Financiamento}

Uma das questões fundamentais ao estabelecimento de atividades inovativas é a disponibilidade de recursos financeiros que possam dar sustentação a projetos inovadores. Há significativa diferença de condições de financiamento entre PMEs e GEs, motivadas pelas distintas condições e garantias que 
empresas de diferentes portes podem apresentar ao mercado financeiro. No caso das PMEs, o financiamento é um gargalo importante a ser enfrentado para a realização de atividades inovativas.

No tocante às fontes de financiamento utilizadas pelas empresas há uma significativa discriminação em relação ao porte, que pode variar de acordo com o país. Grandes empresas têm maior penetração nos mercados financeiros, se beneficiando de linhas de crédito de risco elevado, Private Equity ou emissão de ações, o que pode viabilizar seus projetos financeiramente. Já pequenas empresas tendem a concentrar seu financiamento em recursos internos ou empréstimos bancários (LEE et al, 2015).

A literatura destaca a dificuldade de explicar como restrições ou a falta de crédito disponível afeta o desempenho de P\&D das empresas e, portanto, tal questionamento é recorrente. Acredita-se que há três respostas para isso: a assimetria de informação, que pode ser decisiva para investimento em P\&D uma vez que tais investimentos se realizam no longo prazo com elevados custos de ajustes; a sensibilidade de gastos em P\&D com disponibilidade de recursos internos da firma e o fluxo de caixa; e, por fim, dificuldades de verificar os constrangimentos de financiamento usando modelos que consideram diversos canais de financiamento externos (MANCUSI e VEZZULLI, 2014).

Diversos resultados encontrados na literatura de referência reforçam a existência dessas restrições:

- Mancusi e Vezzulli (2014) confirmam a hipótese de que as restrições de crédito têm impacto negativo na probabilidade de investir em $\mathrm{P} \& \mathrm{D}$, a partir de uma amostra firmas italianas;

- Resultados semelhantes, também para firmas italianas, mostram que as pequenas empresas que sofrem com problemas financeiros tem uma probabilidade de inovar menor que outras companhias; além disso, há um efeito de feedback entre a decisão de inovar e a probabilidade de ter problemas financeiros, dito de outra forma, a decisão de realizar atividades inovativas tem grande sensibilidade a flutuações financeiras - como no caso da crise de 2008 - que possam levar à situação de constrangimentos financeiros para a empresa, principalmente em firmas de setores baseados em tecnologia (BRANCATI, 2015);

- Czarnitzki e Hottenrott (2011), utilizando uma base de dados para firmas alemãs, concluem que a disponibilidade de fluxo de caixa e de recursos internos é primordial para realização de investimento em $\mathrm{P} \& \mathrm{D}$, principalmente para firmas pequenas e jovens que já enfrentam dificuldades de financiamento. Encontram ainda uma relação monotônica entre restrição de capital e tamanho da firma, pois quanto menor a firma maior a possibilidade de haver restrições de capital.

- Essa conclusão é convergente com os resultados de Winker (1999), que por meio de uma base de dados de empresas do oeste alemão para o período de 1982-1991, aponta que firmas mais velhas têm menor risco de enfrentar constrangimentos financeiros. Os autores concluem ainda que no caso da Alemanha, a política monetária pode auxiliar no entendimento das restrições de financiamento para PMEs inovadoras.

- Resultados encontrados por Lee et al (2015) para firmas coreanas apontam que PMEs inovadoras têm maior dificuldade em acessar financiamento, e que no cenário geral há uma piora na oferta de financiamento pós-crise. Por outro lado, apesar dos constrangimentos de crédito, a distância entre o percentual de PMEs que inovam e que obtiveram sucesso em conseguir financiamento daquelas que não inovam e conseguem financiamento diminuiu. Os autores também sugerem que firmas inovadoras têm maior demanda por capital externo e financiamento a partir de 2008 .

O tipo de capital a ser utilizado pelas PMEs inovadoras pode, também, variar de acordo com o país analisado. Enquanto em alguns países como os anglo-saxões, primordialmente EUA e Reino Unido, há um padrão de financiamento empresarial por meio do mercado financeiro, de emissão de ações e fundos de capital de risco (Venture Capital e Private Equity), outros países da Europa, como Itália e Alemanha, têm maior peso do financiamento de PMEs inovadoras no sistema bancário (WINKER, 1999). A isso se devem os diferentes níveis de desenvolvimento dos mercados financeiros e de capitais desses países, à proximidade que o setor bancário tem do setor produtivo, e às preferências das empresas, que podem utilizar recursos internos para financiar suas atividades inovadoras, como é o caso de firmas europeias (REVEST e SAPIO, 2012).

Além disso, esses resultados apresentam implicações sobre política econômica, sendo que o setor público pode ter um papel mais ativo para tornar possível que as atividades inovativas de empresas que não consigam se financiar tornem-se viáveis (REVEST e SAPIO, 2012). 


\subsection{Apoio do governo e políticas públicas}

O Estado e suas estratégias de política públicas desempenham um papel importante em prover condições para inovação em PMEs. Tentativas de apoiar o processo inovativo por meio de políticas de desenvolvimento podem ser consideradas decisivas na formação e upgrade de SNIs. A atuação governamental junto às empresas, criando institucionalidade e organizações que possam permitir o melhor desenvolvimento, difusão e spillovers do conhecimento, é fundamental para o estímulo às atividades inovativas das empresas.

No tocante às PMEs, o apoio do governo não visa apenas minimizar ou ultrapassar falhas de mercado. Este também se concretiza como uma tentativa de promoção de inovação, em uma estratégia de desenvolvimento mais ampla, em resposta aos constrangimentos frequentemente enfrentados por essas empresas. Para atingir os objetivos de promover um ambiente propício às inovações e ao empreendedorismo, o governo pode atuar de forma direta ou por meio de incentivos. Dentre os instrumentos mais utilizados se destacam: compras governamentais, incentivos fiscais ou créditos fiscais, criação de "pontes" entre organizações de pesquisa e empresas, criação de institutos tecnológicos e unidades públicas de pesquisa, financiamento direto de pesquisa, apoio ao mercado de capitais para inovação, desenvolvimento de infraestrutura e subvenção econômica (MARTIN e SCOTT, 2000).

É importante notar que diferentes setores têm fontes de inovação diversas e, portanto, diferentes instrumentos de política devem ser mobilizados para enfrentar a problemática sobre a inovação presente em cada setor (MARTIN e SCOTT, 2000). Ao identificar qual é a fonte de inovação para os diversos setores industriais, devem-se utilizar diferentes instrumentos na formação das políticas públicas, e assim o governo pode desenhar sua estratégia de apoio à inovação.

Das dificuldades mais recorrentemente enfrentadas por PMEs inovadoras, o financiamento de suas atividades inovativas é uma questão fundamental. Pequenas empresas se deparam com barreiras para encontrar financiamento que viabilizem seus projetos de inovação. Parte dessa dificuldade, como já dito anteriormente, se deve à grande quantidade de ativos intangíveis, assimetrias de informação, dentre outros fatores. Nesse sentido, as políticas públicas podem desempenhar um papel importante, seja em desenvolver um mercado de capitais acolhedor às PMEs, seja por via de financiamento direto e/ou incentivo fiscal à inovação. Um conjunto de políticas adotadas podem se condensar na forma de um programa de apoio explícito.

Durante os anos 1980, o Governo dos EUA chegou a um entendimento de que as PMEs estadunidenses haviam perdido competitividade internacional durante as duas décadas passadas e, em resposta a isso, foi implementado o Small Business Innovation Research (SBIR), como um instrumental capaz de apoiar a inovação e estimular o aumento de competitividade das empresas de menor porte estadunidenses. Esse programa consistia em dirigir uma parcela do orçamento do governo norte americano e suas agências para financiamento de negócios com PEs inovadoras. Agências públicas de P\&D dos EUA também teriam que alocar parte de seu orçamento para PMEs.

O SBIR foi organizado em três etapas: a primeira fase orientada pelo mérito técnico-científico para análise da viabilidade do projeto; a segunda fase, com foco na comercialização dos projetos aprovados na fase anterior; e a terceira, que envolve financiamento privado adicional para a comercialização da tecnologia. Desse modo, o programa SBIR chegou a representar cerca de $60 \%$ do financiamento público para PMEs estadunidenses em 1995 (AUDRETSCH, 2003).

O foco das políticas previstas pelo SBIR foi aumentar a competitividade global de PMEs estadunidenses, principalmente daquelas baseadas em conhecimento. Também foi notável o desenvolvimento do programa, que reconheceu a importância de PEs inovadoras na geração de crescimento econômico e competitividade, a despeito do estabelecimento contínuo de políticas de desregulamentação e privatização (AUDRETSCH, 2003). O autor ainda sugere que o programa conseguiu atingir seus objetivos uma vez que garantiu maior índice de sobrevivência das PMEs beneficiadas, além de estimular o empreendedorismo entre os pesquisadores e financiar startups.

O sucesso de programas de apoio à inovação, realizados pelo governo tem sido alvo de intensa discussão acadêmica. Muitos autores se dedicaram a investigar a eficiência e eficácia de tais programas, uma vez que utilizam recursos públicos e, assim, devem ter um retorno à sociedade que os financia. Esse 
debate, com conclusões diversas, visa apoiar a ampliação ou questionar os resultados de tais programas, levantando questionamentos sobre seus benefícios, em resposta ao uso de recursos públicos.

Embora tradicionalmente menos presentes na literatura de referência, os trabalhos que dedicam-se à avaliação de políticas públicas com foco em PMEs ampliaram-se nos últimos anos. Embora se utilizem metodologias diversas, diferenças na definição do que sejam PMEs, programas mais ou menos abrangentes e períodos de análise igualmente distintos, em geral se encontram benefícios nos gastos públicos de estímulo às atividades inovativas (REVEST e SAPIO, 2012).

Avellar e Botelho (2016), no desenvolvimento do estudo, apresentaram seis trabalhos que buscam investigar a existência de efeito crowding out ou efeito additionality respeitando uma discriminação por porte de empresa. Desses trabalhos, cinco rejeitam a hipótese de efeito substituição ou crowding out e o sexto reconhece o efeito additionality para PEs, enquanto para grandes e médias ocorra crowding out. Outros sete trabalhos que não focam em PEs, ou em um recorte por tamanho da firma, também apresentam resultados majoritariamente de efeito additionality dos recursos públicos aos privados.

Para o Brasil, Avellar e Botelho (2016) propõem uma comparação entre empresas brasileiras que receberam algum tipo de apoio e outras que não receberam, utilizando o método Propensity Score Matching (PSM). Utiliza-se os dados da Pintec (2008), cuja amostra consiste em 6981 PEs e 5313 médias empresas, além de 1656 grandes empresas. Em sua conclusão as autoras sugerem que há melhores resultados inovativos para empresas que foram beneficiadas e principalmente maiores gastos em atividades inovativas. As pequenas e médias empresas têm, respectivamente, $125 \%$ e $173 \%$ de aumento nesses indicadores.

Além de incentivos fiscais e estímulos ao aumento de gastos em $\mathrm{P} \& \mathrm{D}$ induzidos pelo governo, o fornecimento de mão de obra qualificada, por meio de políticas educacionais, e o incentivo à formação de redes de colaboração, podem ser também ser importantes para realização de inovação nas PMEs. Dentre essas políticas alternativas que podem ser adotadas pelo governo, as compras governamentais podem também ser um instrumento eficiente e de grande importância, ainda que tenham grandes desafios a serem enfrentados. Atuando de modo ativo na aquisição de bens ou serviços, o governo pode se tornar um consumidor inteligente, que pode dar viabilidade comercial a um novo produto ou serviço, promovendo assim o sucesso de uma inovação, em um processo de estímulo aos resultados de saída inovativa.

Entretanto, tal instrumento pode enfrentar dificuldades em estimular atividades inovativas em PMEs. Isso ocorre por diversos motivos, como dificuldades de lidar com contratos complexos, falta de feedback entre o governo e a empresa e muitas qualificações pré-determinadas para contratação, sendo necessárias medidas de simplificação de procedimentos, informação mais clara para que PEs possam ter condições de competir com grandes firmas para ganhar contratos de fornecimento para o governo (UYARRA, 2014).

Tanto esses resultados, como os encontrados por Foreman-Peck (2013), argumentam que a colaboração entre PMEs e outras organizações, ou entre as próprias PMEs, podem ser determinantes para realização de inovação de forma eficiente. Dessa forma a criação de redes de cooperação pode atuar no sentido de superar dificuldades típicas de PEs, como em economias de escala. No próximo item será tratada a questão da cooperação.

\subsection{Cooperação e informação externa}

Outro componente que pode ter impacto significativo no desenvolvimento de atividades inovativas por parte das empresas é a presença de cooperação ou aquisição de conhecimento e/ou informação externa. Esse é um dos fatores que podem ser determinantes para o desenvolvimento de inovações de qualquer tipo e que, pela sua importância, também é alvo de investigação das pesquisas de inovação baseadas no Manual de Oslo, tais como CIS e PINTEC.

A aquisição de conhecimento externo pode também ser interpretada como a presença de spillovers de conhecimento dentro de uma indústria, que pode ajudar a estabelecer um ambiente propício ao desenvolvimento de inovações. Além disso, a cooperação tem por objetivo estabelecer laços entre diferentes organizações que visam compartilhar conhecimento em direção a atingir um objetivo comum. Normalmente, são considerados atores de cooperação empresas do mesmo grupo econômico, outras empresas da mesma indústria ou mesmo fora dela, universidades, centros de pesquisa públicos e privados, centros de tecnologia, associações ou organizações setoriais, dentre outros. 
O impacto da cooperação sobre a manutenção ou surgimento de atividades inovativas pode variar e, no caso de PMEs, ele ainda pode ser diferente daqueles observados em GEs. Além disso, o próprio tamanho da empresa pode acarretar dificuldades em estabelecer e manter redes de cooperação ativas. As dificuldades derivam da falta de recursos internos à firma e de mão de obra especializada para ter contato contínuo com agentes fora das fronteiras da empresa (ROGERS, 2004).

É válido destacar que PEs podem ser ainda mais dependentes de aquisição de conhecimento externo do que grandes empresas, devendo isso ao fato de que há dificuldades de implementar $\mathrm{P} \& \mathrm{D}$, laboratórios e centros de pesquisa internos, e consequentemente, de gerar conhecimento de forma autônoma (ACS et al., 1994).

Acs et al. (1994), ao analisar dados do U.S. Small Business Administration's Innovation Data Base no ano de 1982, por meio de um modelo Tobit, concluem que, de fato, pequenas e grandes empresas diferem em relação à importância de spillovers e geração de conhecimento interno. Enquanto grandes empresas tem P\&D privado corporativo como principal motor que promove saída de inovação, e alimenta atividades inovativas, em PEs esse papel pode ser desempenhando por agentes externos.

Nesse caso analisado, com foco na relação com universidades, a proximidade geográfica serve de catalisador para atividades inovativas em firmas de todos os portes. Entretanto, tem impacto maior em PEs. As atividades inovativas de PEs respondem mais a pesquisas de universidades do que a gastos em P\&D da própria indústria. Isso pode ser um forte indicador de que spillovers de conhecimento gerado em universidades podem ter grande impacto nas atividades e resultados inovativos de PEs (ACS et al., 1994).

Embora os efeitos dos spillovers sobre o comportamento inovativo de PMEs sejam considerados importantes, não é grande a quantidade de trabalhos que busca investigar essa relação. Dentre esses trabalhos, pode-se citar Chun e Mun (2012). Utilizando de uma análise mais ampla do que a proposta por Acs et al. (1994), os autores buscam explicar a importância em adquirir conhecimento externo pelas PMEs ao promover maior capacidade de absorção e, consequentemente, estarem mais propensas a exercer cooperação em P\&D. A partir de uma amostra do Korean Innovation Survey (KIS), que também tem sua fundamentação metodológica no Manual de Oslo, tal como a CIS e PINTEC, no período de 2001-2002, os resultados apontam que a presença de spillovers tem um papel importante na decisão das PMEs de cooperar em P\&D, e que esse efeito é ainda maior em empresas menores.

Quanto à análise dos diferentes parceiros, os efeitos de spillovers têm maior impacto na cooperação das PMEs com instituições de pesquisa e universidades, confirmando o que foi apresentado por Acs et al. (1994), e menor com relação a compradores e fornecedores. Os efeitos dos spillovers também são maiores em empresas menores, em qualquer tipo de inovação.

Outros fatores, como melhorias nas relações de apropriabilidade, têm também impactos positivos sobre a realização de cooperação de P\&D em PMEs, uma vez que as empresas passam a ter maior controle sobre a saída de inovação. Também, é sugerido que spillovers têm importantes efeitos positivos sobre cooperação institucional, de universidades e centros de pesquisa, mas não tão fortes em cooperação vertical, de fornecedores e compradores (CHUN e MUN, 2012).

Contudo, muito embora spillovers possam ser determinantes para explicar a importância da cooperação de $\mathrm{P} \& \mathrm{D}$, firmas que já tenham atividades internas de $\mathrm{P} \& \mathrm{D}$ apresentam maior capacidade de realizar cooperação de P\&D (CHUN e MUN, 2012 e MUSCIO, 2007), e esse não é um efeito apenas casual. A capacidade que a firma tem de absorver e processar conhecimento externo, ou a sua capacidade de absorção, ajuda a explicar por que algumas PMEs podem ter maior sucesso inovativo. Alguns elementos podem contribuir para a formação da capacidade de absorção, como a influência do passado ou path dependence, e as atividades internas de $\mathrm{P} \& \mathrm{D}$, que podem desenvolver a capacidade das firmas de identificar, assimilar e explorar o conhecimento no ambiente, tornando assim possível o processo de aprendizado (COHEN e LEVINTHAL, 1990).

Muscio (2007) se aprofunda nesta temática da capacidade de absorção ao analisar um conjunto de PMEs da região de Lombardia na Itália, uma região predominantemente industrial, com grandes gastos em $\mathrm{P} \& \mathrm{D}$ privado e forte presença de universidades. Os resultados do modelo utilizado sugerem que a capacidade de absorção tem um forte impacto na predisposição da firma em realizar cooperação, e que a realização prévia de algum tipo de $\mathrm{P} \& \mathrm{D}$ interno pode tornar as firmas aptas a entrar em contato com parceiros externos, ou seja, a intensidade de P\&D tem ligação direta com a capacidade de absorção. A 
presença de empregados com graduação e com maior qualificação, além de programas contínuos de treinamento também têm efeito positivo sobre a capacidade de absorção e, consequentemente, na cooperação, principalmente com universidades (MUSCIO, 2007).

Dentre as contribuições de Muscio (2007), está a demonstração que recursos humanos qualificados e atividades de $P \& D$ interno são necessários para que haja interação externa, uma vez que tais requisitos formam uma curva de aprendizagem determinante em aprimorar a capacidade de absorção. Entretanto, para PMEs são exatamente as atividades internas de P\&D as que têm maiores dificuldades de se desenvolver, em parte devido à falta de funcionários qualificados (NOTEBOOM, 1994; ROTHWELL, 1989).

Outros métodos também são utilizados para buscar explicar a motivação que PMEs devem ter para realizar cooperação com outras organizações. Ceci e Iubatti (2012) utilizam um método de análise de conteúdo, baseado em textos, entrevistas, discursos políticos, livros, jornais para obter informação e dados qualitativos a respeito de PMEs do setor automobilístico italianas, da região de Abruzos. Os resultados da pesquisa sugerem que a difusão da inovação é ativada por relações pessoais como a presença de confiança, compartilhamento de valores e objetivos comuns. A estratégia de inovação é difundida em redes, o que depende da variedade das relações entre os agentes.

Na mesma direção, ao analisar um conjunto de empresas australianas entre os anos de 1994 e 1997 , Rogers (2004) demonstra por meio de um modelo de regressão Probit, que há um grau de persistência de atividades inovativas entre 1995 e 1997 nas empresas que participam de redes de cooperação. Os resultados do estudo ainda sugerem que o impacto de redes de firmas é maior em pequenas empresas do que em grandes, levando à conclusão de que PEs industriais são fortemente estimuladas a inovar quando participam de redes.

À luz dessas referências, na próxima seção apresenta-se a parte empírica do estudo. Utiliza-se as bases de dados da PINTEC e CIS para sistematizar um conjunto de indicadores que caracterizam as atividades inovativas de PMEs. A título de comparação, também forma sistematizados os mesmos indicadores para grandes empresas. Busca-se assim, identificar as diferenças entre os países em termos de taxas de inovação, tipos de gastos em atividades inovativas, cooperação e apoio do governo.

\section{Atividades inovativas das empresas, segundo porte e país}

A análise das atividades inovativas das empresas de pequeno porte será realizada mediante a sistematização de duas bases de dados: a Pesquisa de Inovação Tecnológica (PINTEC) do IBGE, e a Community Innovation Survey (CIS), elaborada pela Eurostat, a agência de estatística da União Europeia. Ambas as pesquisas são fundamentadas no Manual de Oslo, que visa orientar, padronizar e estabelecer conceitos e metodologias para mensurar inovação. As pesquisas também apresentam um recorte por porte de empresa, considerando o número de funcionários. A classificação adotada é que pequenas empresas (PEs) têm de 10 a 49 funcionários, médias empresas de 50 a 249 e grandes empresas (GEs) 250 funcionários ou mais. Para apresentação deste artigo foram considerados dois períodos: o período 1, correspondente a PINTEC 2008 e a CIS6 (ambas período de 2006 a 2008); e o período 2, correspondente a PINTEC 2011 (períodos de 2009 a 2011) e CIS8 (períodos 2010 a 2012).

\subsection{Taxa de inovação}

Dentre os indicadores que buscam expor o desempenho dos resultados inovativos das empresas pesquisadas está a Taxa de Inovação. Tal indicador é obtido a partir da divisão da quantidade de empresas inovadoras pelo total de empresas da amostra. A Tabela 1 explicita a taxa de inovação, que foi sistematizada por países, porte e períodos.

O primeiro destaque é que a esperada relação entre porte e taxa de inovação se verifica para todos os países, ou seja, quanto maior o porte, maior a taxa de inovação. Entretanto, há muitas variações entre países e períodos e a diferença entre as taxas de inovação pode ser muito pequena, como no Reino Unido, em que a taxa é muito semelhante entre os segmentos analisados.

De acordo com a média percebe-se que a taxa de inovação tem queda do primeiro para o segundo período no total das empresas. Esta ocorrência foi observada na Noruega, Portugal e Brasil, mas com maior 
intensidade na Alemanha, República Tcheca e Espanha ${ }^{3}$. É importante frisar que nesse período houve a crise financeira de 2008/2009, e uma consequente queda no produto de diversos países no ano de 2009. A retração nos fluxos financeiros internacionais pode ter tornado o crédito mais custoso, dificultando o financiamento das atividades inovativas no segundo período.

Entretanto, em outros países, como França, Itália, Suécia e Reino Unido, houve melhora no indicador no segundo período em relação ao primeiro para o total das empresas. O Brasil apresenta taxa de inovação de $41,18 \%$ e $38,16 \%{ }^{4}$ no primeiro e segundo período respectivamente, taxas significativamente menores que grande parte dos países europeus. Diferentemente do outros países com estrutura produtiva mais complexa, a Espanha apresenta taxa de inovação mais parecida com a do Brasil, de 43,54\% e 33,65\% no primeiro e segundo período, respectivamente. Por outro lado Polônia, Romênia e Hungria, que têm PIBs per capita próximos ou menores que o brasileiro, apresentaram indicador menor.

As PEs apresentam médias da taxa de inovação de 43,98\% e 41,80\% no período um e dois respectivamente e, portanto, menores que as de porte grande ou médio. O desvio padrão amostral de 0,139 no primeiro período cai para 0,119 no segundo, indicando que houve uma pequena convergência entre as taxas de inovação dos países. As taxas de inovação de PEs para o Brasil são de 39,73\% e 36,37\% nos respectivos primeiro e segundo períodos, um desempenho não muito distante do observado em países do Leste Europeu.

O desempenho das PEs brasileiras apresenta considerável diferença com a de outros países que têm estruturas produtivas mais complexas, como Alemanha, França e Reino Unido, onde a taxa de inovação no primeiro período é de $77,32 \%, 45,03 \%$ e $42,97 \%$ para esse segmento, todas com resultado superior ao registrado no Brasil. Essa defasagem aumenta no segundo período, uma vez que França, Reino Unido, Países Baixos e Suécia apresentam melhora do indicador de taxa de inovação, movimento inverso ao verificado no Brasil. Se destaca os resultados da Espanha, que apresentou uma expressiva piora na taxa de inovação de PEs, chegando a 29,02\% no segundo período, menor que a verificada no Brasil e comparável à da Hungria.

Tabela 1 - Taxa de inovação para Brasil e países europeus segundo porte, em porcentagem

\begin{tabular}{|c|c|c|c|c|c|c|c|c|}
\hline \multirow[t]{2}{*}{ País } & \multicolumn{2}{|c|}{ Total das empresas } & \multicolumn{2}{|c|}{$\begin{array}{l}\text { Empresas } 10 \text { a } 49 \\
\text { funcionários }\end{array}$} & \multicolumn{2}{|c|}{$\begin{array}{l}\text { Empresas } 50 \text { a } 249 \\
\text { funcionários }\end{array}$} & \multicolumn{2}{|c|}{$\begin{array}{l}\text { Empresas com } 250 \text { funcionários } \\
\text { ou mais }\end{array}$} \\
\hline & $\mathrm{P} 1$ & $\mathrm{P} 2$ & P1 & $\mathrm{P} 2$ & $\mathrm{P} 1$ & P2 & P1 & P2 \\
\hline Alemanha & 79,91 & 66,94 & 77,72 & 63,30 & 84,25 & 74,31 & 94,63 & 92,20 \\
\hline Áustria & 56,23 & 54,42 & 50,92 & 48,73 & 70,18 & 70,86 & 86,39 & 84,02 \\
\hline Bélgica & 58,13 & 55,56 & 53,99 & 50,90 & 71,89 & 68,77 & 83,78 & 83,47 \\
\hline Brasil & 41,18 & 38,16 & 39,73 & 36,37 & 43,66 & 43,08 & 62,11 & 56,37 \\
\hline Dinamarca & 51,92 & 51,07 & 47,87 & 47,53 & 60,59 & 57,45 & 80,18 & 79,71 \\
\hline Espanha & 43,54 & 33,65 & 40,09 & 29,02 & 59,15 & 55,74 & 78,28 & 78,20 \\
\hline França & 50,18 & 53,44 & 45,03 & 49,15 & 66,50 & 66,22 & 81,77 & 81,05 \\
\hline Hungria & 28,94 & 32,47 & 24,46 & 28,42 & 39,55 & 42,78 & 67,12 & 67,23 \\
\hline Itália & 53,24 & 56,15 & 50,23 & 53,41 & 71,73 & 71,43 & 81,90 & 84,39 \\
\hline Noruega & 49,18 & 44,68 & 44,58 & 42,03 & 63,69 & 52,26 & 72,78 & 61,08 \\
\hline Países Baixos & 44,87 & 51,37 & 40,15 & 47,36 & 59,88 & 65,68 & 77,94 & 68,49 \\
\hline Polônia & 27,94 & 23,00 & 22,41 & 17,43 & 39,97 & 35,77 & 66,71 & 63,90 \\
\hline Portugal & 57,81 & 54,62 & 54,64 & 51,26 & 69,20 & 66,78 & 89,56 & 87,27 \\
\hline Reino Unido & 45,62 & 50,27 & 42,97 & 48,67 & 54,94 & 56,71 & 58,33 & 56,15 \\
\hline Romênia & 33,31 & 20,67 & 29,85 & 18,25 & 40,85 & 26,57 & 58,90 & 40,05 \\
\hline Suécia & 53,66 & 55,93 & 49,20 & 52,79 & 67,41 & 65,62 & 85,24 & 81,86 \\
\hline Turquia & & 48,55 & & 46,48 & & 56,09 & & 66,38 \\
\hline Média & 48,19 & 45,69 & 43,98 & 41,80 & 60,91 & 57,29 & 77,40 & 73,80 \\
\hline Desvio padrão & 0,133 & 0,117 & 0,139 & 0,119 & 0,135 & 0,123 & 0,097 & 0,122 \\
\hline
\end{tabular}

\footnotetext{
${ }^{3} \mathrm{Na}$ análise que se segue, as observações sobre os sistemas de inovação dos países, em termos de seu grau de desenvolvimento, segue a classificação proposta por Filippetti e Archibugi (2011), a saber: 1) Catching-up countries (Romênia, Bulgária, Polônia); 2) Frontrunners (Finlândia, Alemanha, Suécia, Suíça); 3) Declining (Dinamarca, Países Baixos, Reino Unido, França); 4) Lagging-behind (Hungria, Itália, Espanha, Portugal). Os países do grupo 3 são considerados os que têm sistemas de inovação mais desenvolvidos e, juntamente com os do grupo 2, constituem o grupo as economias mais industrializadas e com estruturas produtivas mais complexas.

${ }^{4}$ A taxa de inovação para o Brasil foi calculada considerando as empresas com projetos incompletos e/ou abandonados. Essa opção metodológica foi tomada de modo a compatibilizar os dados brasileiros com a CIS, que considera esse tipo de empresa como inovadora. Por isso, a taxa de inovação é ligeiramente superior à divulgada pela PINTEC.
} 
A média da taxa de inovação para empresas e médio porte (50 a 249 funcionários) para os países analisados é maior que a média da taxa de inovação das PEs. Há uma pequena variação no desvio padrão, de 0,135 para 0,123 , do primeiro para o segundo período. A taxa de inovação para médias empresas no Brasil é de 43,66\% e 43,08\% no primeiro e segundo períodos, evidenciando uma queda. A taxa de inovação para médias empresas do Brasil foi maior apenas que as da Hungria, Polônia e Romênia em ambos os períodos. Percebe-se, também, que nenhum desses países apresenta a complexidade produtiva verificada no Brasil.

Para empresas de grande porte, com mais de 250 funcionários, as taxas de inovação são maiores que as das PMEs, apresentando uma média superior a 70\% em ambos os períodos. O desvio padrão é menor no primeiro período, de 0,09, enquanto no segundo é de 0,12 . Mais uma vez o Brasil apresenta desempenho abaixo da média, com diferença ainda maior quando comparado com países mais ricos. Enquanto Alemanha, Bélgica, França, Suécia, Itália, e Portugal apresentam taxas sempre superiores a 80\%, o Brasil tem taxas de $62,11 \%$ no primeiro e $56,37 \%$ no segundo período. Resultados mais próximos ao brasileiro são encontrados no Reino Unido, 58,33\% e 56,15\% no período um e dois, respectivamente.

Note-se também que há queda na média das taxas de inovação dos países analisados do primeiro para o segundo período. Dessa forma é possível concluir que houve redução na taxa de inovação na maior parte dos países analisados no período, em todos os portes de empresas. Esse resultado possivelmente relaciona-se à crise financeira internacional de 2008/2009 e seus efeitos de retração de crédito.

Os resultados também são compatíveis com a literatura de referência em relação ao comportamento inovativo de PMEs. Essas empresas costumam enfrentar maiores dificuldades no financiamento de suas atividades inovativas, além de frequente falta de recursos humanos capazes de fixar processos inovadores. A diferença nas Taxas de Inovação de acordo com o porte das empresas é ainda maior no Brasil, Espanha, Hungria, e alguns outros países do Leste Europeu. Para melhor análise desses resultados é preciso investigar quais as escolhas de tipo de inovação, e quais atividades inovativas são mais utilizadas por essas empresas nesses países, como será visto a seguir.

O gráfico 1 apresenta os resultados segundo a discriminação de tipo de inovação. São considerados dados do segundo período para empresas que inovaram em produto e/ou processo. São desconsideradas empresas com atividades inovativas suspensas e/ou abandonadas e/ou atividades inovativas em curso, observando-se apenas aquelas empresas que efetivaram inovações no período.

Os resultados apontam que Reino Unido, Noruega e Alemanha estão entre os países com maior participação de inovações de produto das PEs, com indicadores próximos aos 50\%. Na outra ponta, o Brasil é o país com o menor indicador, apenas 28,14\%, com Espanha e Portugal apresentando resultados parecidos, com cerca de $30 \%$ de suas inovações no tipo produto.

As PEs da Espanha são as com maior participação das inovações do tipo processo, com 50,68\%, seguidas pelo Brasil, com 49,87\%. Outros países com destaque em resultados de inovações de processo são Portugal e Romênia. Reino Unido, Noruega e Alemanha são os de menor participação de inovações de processo com cerca de $30 \%$.

As inovações de produto e processo, conjuntamente, correspondem a 16,69\% dos tipos de inovação para Espanha. O Brasil está entre a metade dos países com menor participação de inovações de produto e processo, cerca de 21,99\%. Nesse quesito PEs da Alemanha, Reino Unido, Noruega, Suécia e Espanha apresentam resultados ligeiramente menores que o Brasil.

Para as médias empresas, novamente o Brasil ocupa a última posição, com 27,62\% das inovações no tipo de produto, independentemente de outro tipo de inovação. Portugal, Turquia e Espanha, com respectivamente $32,73 \%$ 33,64\% e 34,27\% de suas inovação do tipo produto, também estão entre os menores resultados, enquanto Noruega, Reino Unido e Suécia apresentam a maior proporção de inovação em produto para médias empresas, todos com parcela de mais de $43 \%$. Mais de $40 \%$ das inovações de médias empresas são do tipo processo para o Brasil, Portugal e Espanha, sendo alguns dos países com maior parcela e inovação de processo. Noruega, Reino Unido e Alemanha estão entre os que têm menor proporção de inovações em processo, pouco menos de $35 \%$ para todos.

As inovações do tipo produto e processo, aquelas que ocorrem em conjunto sugerindo maior dinamismo inovativo, são mais frequentes na Itália, Portugal e Turquia, com indicadores em torno de $26 \%$. 
Destes, os dois últimos estão entre aqueles que têm maior frequência em inovação do tipo processo. As médias empresas brasileiras estão entre as que menos inovam dessa maneira, com apenas 20,63\% das inovações do tipo produto e processo, muito embora seja um resultado próximo ao verificado na Noruega, Reino Unido e Espanha.

Gráfico 1 - Tipos de inovação, segundo países e portes de empresa (2011)

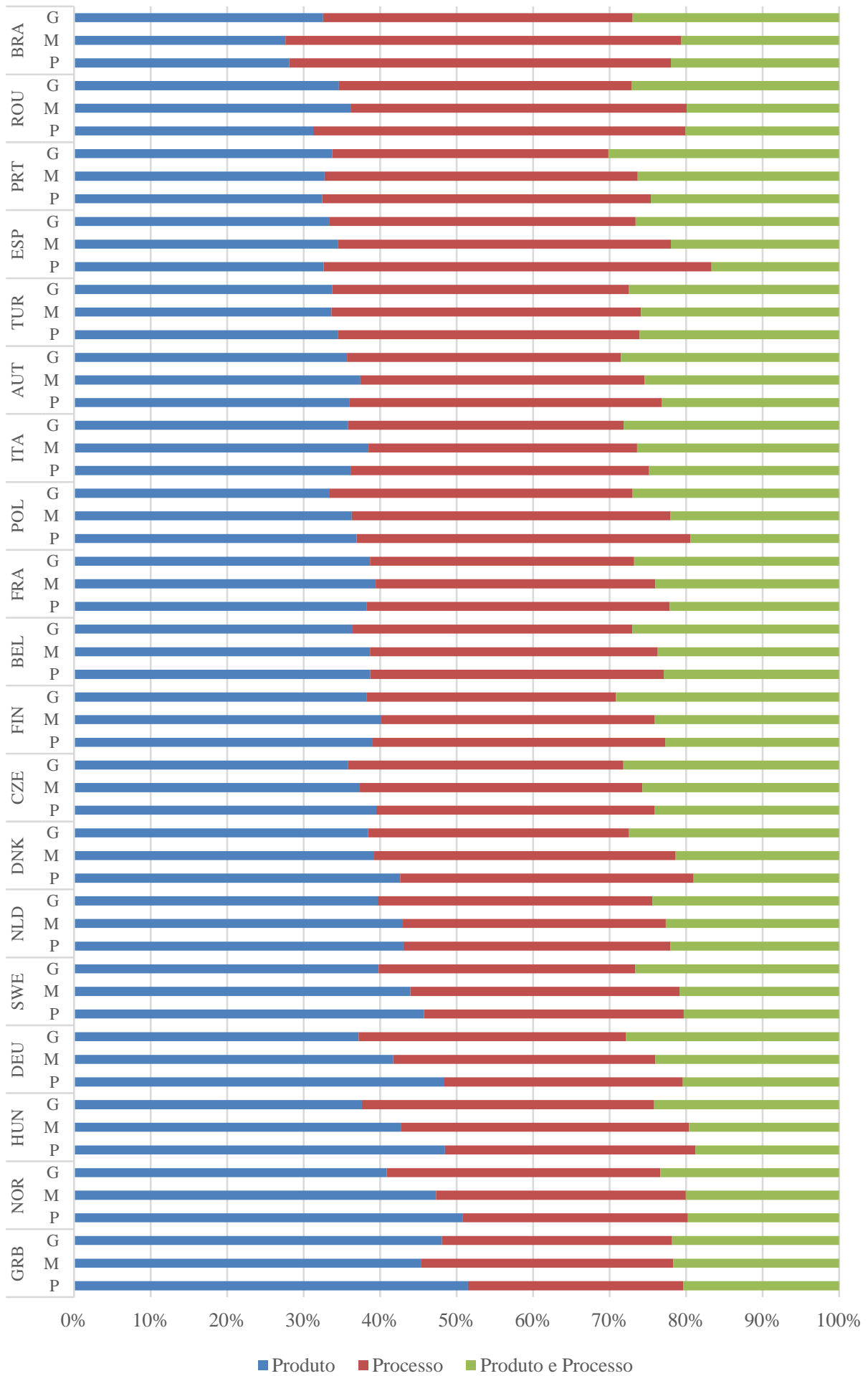

Fonte: Elaboração própria, a partir de dados da CIS e PINTEC. 
O Gráfico 1 também apresenta informações para as grandes empresas. Para esse segmento de empresas, o Brasil apresenta posicionamento semelhante ao observado para os demais portes, predominando inovações de processo sobre as de produto e produto e processo conjuntamente.

Em geral, as grandes empresas apresentam maior diversidade em termos de resultados de inovação, ou tipo de inovação, sendo mais frequentes empresas que inovam conjuntamente em produto e processo que em PMEs. Também é perceptível que países que apresentaram melhores indicadores de taxa de inovação são aqueles que têm maior diversidade em tipos de inovação, ou têm melhor resultado em inovar em produto e processo, conjuntamente, ou em inovação de produto, quando comparados com os que apresentam taxas de inovação menores.

\subsection{Esforço inovativo: tipos de gastos e atividades inovativas}

A investigação sobre o perfil dos gastos em atividades inovativas justifica-se pela importância com que os diferentes tipos de gasto podem ter no processo inovativo, e na repercussão sobre os resultados inovativos. Na seção anterior foi identificado que as empresas brasileiras têm maior parcela de seu processo inovativo expresso em inovações de processo, com maior destaque para PMEs, com cerca de 50\% das inovações do tipo processo. Essa realidade é distinta da verificada em países europeus, como Alemanha, Dinamarca, França e Reino Unido, que apresentam uma proporção muito maior de inovações em produto, ou em produto e processo.

A Tabela 2 apresenta os resultados do indicador de esforço inovativo, em uma tentativa de mostrar o quanto os gastos em inovação representam no faturamento das empresas. Tal indicador é feito calculando os gastos monetários em atividades inovativas sobre o faturamento das empresas. Pode haver uma pequena diferença entre os resultados da CIS e da PINTEC, uma vez que a primeira considera o faturamento total das empresas, e a segunda a receita líquida de vendas, ou seja, a receita de vendas de bens e serviços descontados impostos, descontos comerciais e vendas devolvidas.

Considerando o total de empresas, no primeiro período, com exceção da Suécia, o Brasil apresentou o maior esforço inovativo, de 2,85\%. Já no segundo período Alemanha, Dinamarca e Suécia e outros países apresentaram maior esforço que o brasileiro, que registrou queda no indicador para $2,56 \%$. Ao contrário da queda registrada no Brasil, nos países citados anteriormente houve significativo aumento do indicador de esforço inovativo.

No período analisado houve considerável incerteza, com a repercussão da crise financeira de 2008/2009. Em crises financeiras frequentemente são registradas restrições para financiamento de PMEs, principalmente aquelas que inovam (BRANCATI, 2015; LEE et al, 2015), o que pode inviabilizar alguns projetos inovativos de PMEs. O Brasil apresentou uma queda no indicador no segundo período, para as PEs, de $4,40 \%$ para $4,13 \%$. É válido notar que esse não foi o mesmo movimento observado em algumas economias europeias.

A média do esforço inovativo para PEs sofreu uma alteração muito pequena, de um período para o outro, enquanto o desvio padrão permaneceu constante, indicando que o período de crise financeira internacional não afetou de maneira evidente os gastos das PEs. A hipótese de Lee et al (2015) de que há retração da oferta de financiamento para empresas inovadoras em períodos de crise não chega a ser contestada. Embora as pequenas e médias empresas dos países analisados tenham mantido constante, ou aumentado o seu esforço inovativo, não fica evidente quais são as fontes dos recursos de financiamento, se são internos à firma, por empréstimos bancários, recursos governamentais ou outros.

Uma possível explicação para que não tenha havido queda no esforço inovativo entre o primeiro e o segundo período seja o entendimento de que os investimentos em atividades inovativas ocorram de forma contínua, mesmo em períodos de crise, tais investimentos podem resultar em ganhos de longo prazo, como sugere Foreman-Peck (2013).

Tabela 2 - Esforço Inovativo em termos de gastos com atividades inovativas para Brasil e países europeus nos períodos um e dois, em porcentagem

\begin{tabular}{|c|c|c|c|c|c|c|c|c|}
\hline \multirow[t]{2}{*}{ País } & \multicolumn{2}{|c|}{ Total de Empresas } & \multicolumn{2}{|c|}{$\begin{array}{l}\text { Empresas de } 10 \text { a } 49 \\
\text { funcionários }\end{array}$} & \multicolumn{2}{|c|}{$\begin{array}{l}\text { Empresas de } 50 \text { a } 249 \\
\text { funcionários }\end{array}$} & \multicolumn{2}{|c|}{$\begin{array}{l}\text { Empresas com mais de } 250 \\
\text { funcionários }\end{array}$} \\
\hline & $\mathrm{P} 1$ & $\mathrm{P} 2$ & P1 & $\mathrm{P} 2$ & $\mathrm{P} 1$ & $\mathrm{P} 2$ & P1 & P2 \\
\hline Alemanha & 2,18 & 2,79 & 1,15 & 1,37 & 1,10 & 1,44 & 2,68 & 3,43 \\
\hline Áustria & 1,69 & 1,79 & 1,42 & 1,11 & 1,22 & 1,05 & 2,03 & 2,56 \\
\hline
\end{tabular}




\begin{tabular}{|c|c|c|c|c|c|c|c|c|}
\hline Bélgica & 1,93 & 1,79 & 1,16 & 1,29 & 1,90 & 2,66 & 2,57 & 1,64 \\
\hline Brasil & 2,85 & 2,56 & 4,40 & 4,13 & 2,40 & 2,73 & 3,12 & 2,38 \\
\hline Bulgária & 1,02 & 0,69 & 0,37 & 0,30 & 0,95 & 0,34 & 1,41 & 0,74 \\
\hline Dinamarca & & 3,20 & & 1,72 & & 1,38 & & 4,78 \\
\hline Finlândia & 2,76 & 2,27 & 1,85 & 2,20 & 1,56 & 1,10 & 3,34 & 2,78 \\
\hline França & 1,98 & 2,00 & 1,21 & 1,41 & 1,48 & 1,43 & 2,40 & 2,32 \\
\hline Hungria & 1,28 & 1,65 & 1,39 & 0,74 & 0,66 & 3,33 & 1,46 & 1,26 \\
\hline Itália & 1,23 & 1,13 & 1,24 & 1,07 & 1,26 & 1,06 & 1,21 & 1,20 \\
\hline Noruega & 0,85 & 1,10 & 0,93 & 1,51 & 1,05 & 1,17 & 0,75 & 0,95 \\
\hline Países Baixos & 1,69 & 1,38 & 1,21 & 0,72 & 1,30 & 0,87 & 2,23 & 2,14 \\
\hline Polônia & 1,40 & 1,41 & 0,34 & 0,35 & 1,21 & 1,39 & 1,86 & 1,91 \\
\hline Portugal & 1,23 & 1,29 & 0,95 & 1,34 & 1,57 & 1,11 & 1,17 & 1,38 \\
\hline Reino Unido & & 0,79 & & 0,83 & & 1,41 & & 0,60 \\
\hline Rep. Checa & 1,67 & 1,29 & 2,11 & 1,06 & 1,15 & 1,19 & 1,85 & 1,42 \\
\hline Romênia & 1,58 & 0,44 & 0,84 & 0,30 & 0,99 & 0,51 & 2,05 & 0,45 \\
\hline Suécia & 3,18 & 3,64 & 1,34 & 2,03 & 1,42 & 1,28 & 4,82 & 4,90 \\
\hline Turquia & & 3,71 & & 1,88 & & 7,44 & & 2,86 \\
\hline Desvio Padrão & 0,006 & 0,009 & 0,008 & 0,008 & 0,007 & 0,013 & 0,010 & 0,013 \\
\hline
\end{tabular}

Quando são analisados os portes das empresas, percebe-se que as pequenas empresas têm, em média, menor esforço inovativo nos países europeus, enquanto para o Brasil esse é o porte de firma com maior esforço, de 4,40\% no primeiro período. Em empresas de médio porte os países com maior destaque são Bélgica, Turquia e Hungria, já Alemanha, França e Itália têm resultados próximos ou pouco menores que a média de $1,53 \%$ no segundo período. Espanha, que até então tem tido um desempenho parecido com o brasileiro, apresenta um esforço inovativo de $0,74 \%$ e $0,90 \%$ para o primeiro e segundo período, ambos menores que os do Brasil e que as outras grandes economias do Bloco.

Para as GEs, o indicador cresce para quase todos os países entre os períodos analisados, com destaque para Alemanha, Dinamarca, Áustria, França e Suécia, mostrando que GEs gastam consideravelmente mais em atividades inovativas com relação ao faturamento do que PMEs. Essa relação não é observada no Brasil, onde o grupo com indicador mais elevado são as PEs.

Como já destacado anteriormente, no Brasil é registrada uma queda no indicador de esforço inovativo para pequenas e grandes empresas, e apenas para médias empresas houve aumento. A média dos dados mostra que em todos os portes houve aumento do esforço inovativo do primeiro para o segundo período. O destaque para países que apresentaram aumento do indicador de esforço inovativo foram Alemanha e Noruega, para todos os portes de firma.

Além do esforço inovativo, é necessário analisar qual tipo de inovação é mais frequente, e se existe algum padrão seguido pelas empresas de acordo com o porte. Tanto a CIS como a PINTEC consideram cinco formas distintas de gastos: Aquisição de máquinas, equipamentos e softwares; Aquisição de P\&D externo; Atividades internas de P\&D; Aquisição de outros conhecimentos externos; e Outros gastos inovativos. Esse último é considerado apenas para o segundo período, uma vez que para o período um apenas os quatro primeiros são mensurados pela CIS.

A primeira coluna da Tabela 3 intitulada Máquinas apresenta a parcela de gastos com aquisição de máquinas, equipamentos e softwares no total de gastos com atividades inovativas. As PMEs apresentam parcela de gastos com esse tipo de atividade inovativa maior que a de GEs para a maioria dos países. $\mathrm{Na}$ Itália, PMEs têm quase metade de seus recursos de atividades inovativas envolvidos com esse tipo de gasto, enquanto nas GEs esse percentual não ultrapassa os 30\%. Portugal, Suécia e Brasil também apresentam elevadas parcelas desse tipo de gasto nas PMEs, enquanto as GEs gastam proporcionalmente menos. É nítido o padrão de maior participação de gastos em aquisição de máquinas, equipamentos e softwares nas PMEs, comparada às GEs em todos os países, indicando maior diversidade nas escolhas de gastos em atividades inovativas das GEs em relação às de pequeno e médio portes.

No Brasil os gastos com aquisição de máquinas, equipamentos e softwares correspondem a 70,55\% e 53,07\% dos gastos inovativos das PEs, no primeiro e segundo período, respectivamente. Tal desempenho é parecido com os de países do Leste Europeu. A diferença entre o primeiro e segundo período também é identificada na maior parte dos países, como Alemanha, França, Espanha e Países Baixos, que apresentam queda de mais de 20 pontos percentuais na participação desse tipo de gastos nas PEs. A magnitude dessa 
alteração entre os períodos pode ser explicada pela mudança metodológica da CIS entre os períodos, e indica que no segundo período houve mais diversidade nas escolhas de gastos inovativos.

Por outro lado, GEs de Dinamarca, Noruega, Suécia, Países Baixos e França, apresentam parcelas de gastos com esse tipo de atividade inovativa significativamente menores que os verificados nos demais países, com participação de menos de $10 \%$ em alguns casos. As GEs do Brasil despendem aproximadamente $40 \%$ de seus gastos em atividades inovativas com aquisição de máquinas e, ao contrário da maior parte dos outros países, não há queda significativa na parcela desse tipo de gasto do período um para o dois.

Como sugerem Avellar e Botelho (2016), o maior nível de gastos com aquisição máquinas no Brasil pode ser explicado pela influência de programas de apoio governamental e incentivos fiscais destinados a esse tipo de gasto, e que tiveram efeitos positivos, especialmente para as PMEs. Tal aquisição pode ser compreendida também como aquisição de pacotes tecnológicos, ou aplicações desenvolvidas por entidades externas à firma.

A segunda coluna apresenta dados sobre a aquisição de P\&D externo e, de acordo com o apresentado, pode-se inferir que este não é o maior tipo de gastos inovativo realizados pelas empresas, qualquer que seja o porte. Para empresas de 10 a 49 funcionários, a parcela destinada a esse tipo de gasto é menor na maioria dos países, principalmente quando comparada com os resultados da primeira coluna.

Embora para alguns países não haja significativa alteração do primeiro para o segundo período, no Brasil há uma grande diferença entre os períodos. Gastos com aquisição de P\&D externo representam $0,78 \%$ e $10,34 \%$ do total de gastos para pequenas empresas nos períodos um e dois, respectivamente. Nas médias empresas os montantes são de $0,82 \%$ no primeiro período e $9,61 \%$ no segundo. O indicador varia menos para as GEs brasileiras, no período um de 5,41\% para 5,36\% no período dois. Essas parcelas são menores que as verificadas em países de renda elevada como Itália, Suécia, Noruega, Bélgica, Dinamarca, França e Espanha. A grande variação para PMEs pode indicar que no Brasil, no segundo período, houve maior diversidade nos gastos em atividades inovativas. Por outro lado, houve grande retração na Suécia, Áustria e Alemanha.

Tabela 3 - Tipos de gastos com atividades inovativas segundo a participação nos gastos inovativos totais para Brasil e países europeus nos períodos um e dois, em porcentagem

\begin{tabular}{|c|c|c|c|c|c|c|c|c|c|c|}
\hline \multirow{2}{*}{ País } & \multirow{2}{*}{ Porte } & \multicolumn{2}{|c|}{ Máquinas } & \multicolumn{2}{|c|}{ P\&D Externo } & \multicolumn{2}{|c|}{ P\&D interno } & \multicolumn{2}{|c|}{ Conhecimento Externo } & \multirow{2}{*}{$\begin{array}{c}\text { Outros } \\
\text { P2 }\end{array}$} \\
\hline & & $\mathrm{P} 1$ & $\mathrm{P} 2$ & $\mathrm{P} 1$ & $\mathrm{P} 2$ & $\mathrm{P} 1$ & $\mathrm{P} 2$ & $\mathrm{P} 1$ & $\mathrm{P} 2$ & \\
\hline \multirow{3}{*}{ Alemanha } & Pequenas & 52,61 & 30,75 & 6,76 & 3,64 & 34,96 & 36,29 & 5,67 & 2,25 & 27,07 \\
\hline & Médias & 46,14 & 27,02 & 6,23 & 5,30 & 44,17 & 42,96 & 3,46 & 1,38 & 23,35 \\
\hline & Grandes & 34,40 & 28,18 & 11,31 & 10,04 & 51,02 & 42,96 & 3,27 & 1,58 & 17,23 \\
\hline \multirow{3}{*}{ Áustria } & Pequenas & 54,47 & 45,57 & 11,35 & 5,39 & 31,78 & 42,24 & 2,40 & 2,04 & 4,76 \\
\hline & Médias & 39,69 & 26,88 & 10,95 & 8,32 & 45,89 & 59,15 & 3,48 & 3,29 & 2,36 \\
\hline & Grandes & 13,81 & 13,90 & 11,47 & 10,08 & 73,12 & 70,96 & 1,60 & 2,82 & 2,24 \\
\hline \multirow{3}{*}{ Bélgica } & Pequenas & 39,58 & 38,85 & 17,64 & 8,87 & 40,25 & 42,81 & 2,54 & 2,14 & 7,33 \\
\hline & Médias & 25,37 & 34,83 & 12,84 & 7,45 & 59,51 & 51,78 & 2,28 & 3,35 & 2,60 \\
\hline & Grandes & 23,16 & 18,74 & 26,61 & 19,66 & 47,52 & 56,50 & 2,71 & 1,94 & 3,16 \\
\hline \multirow{3}{*}{ Brasil } & Pequenas & 70,55 & 53,07 & 0,78 & 10,34 & 9,20 & 11,41 & 2,93 & 11,41 & 13,76 \\
\hline & Médias & 63,96 & 60,17 & 0,82 & 9,61 & 12,76 & 16,03 & 2,48 & 1,67 & 12,52 \\
\hline & Grandes & 44,03 & 42,56 & 5,41 & 5,36 & 33,06 & 37,09 & 3,20 & 2,82 & 12,18 \\
\hline \multirow{3}{*}{ Dinamarca } & Pequenas & - & 7,44 & - & 15,57 & - & 60,26 & - & 3,63 & 13,09 \\
\hline & Médias & - & 7,43 & - & 21,58 & - & 59,24 & - & 2,32 & 9,44 \\
\hline & Grandes & - & 3,38 & - & 31,53 & - & 59,54 & - & 1,42 & 4,13 \\
\hline \multirow{3}{*}{ Espanha } & Pequenas & 42,92 & 16,31 & 10,48 & 11,23 & 45,98 & 66,73 & 0,62 & 0,47 & 5,27 \\
\hline & Médias & 27,00 & 16,48 & 12,15 & 14,08 & 60,35 & 61,60 & 0,49 & 0,39 & 7,46 \\
\hline & Grandes & 41,05 & 16,68 & 16,41 & 25,68 & 32,06 & 43,28 & 10,48 & 6,97 & 7,39 \\
\hline \multirow{3}{*}{ Estônia } & Pequenas & 73,01 & 71,87 & 2,93 & 5,31 & 17,71 & 19,12 & 6,35 & 0,91 & 2,79 \\
\hline & Médias & 8- & 71,83 & 5,95 & 4,24 & 13,30 & 17,89 & 0,75 & 1,24 & 4,80 \\
\hline & Grandes & 77,25 & 34,78 & 3,61 & 5,55 & 18,95 & 58,02 & 0,20 & 0,64 & 1,00 \\
\hline \multirow{3}{*}{ Finlândia } & Pequenas & 19,78 & 20,34 & 24,91 & 10,93 & 51,46 & 62,64 & 3,85 & 3,12 & 2,97 \\
\hline & Médias & 25,40 & 29,18 & 15,40 & 11,01 & 52,99 & 56,27 & 6,22 & 0,74 & 2,80 \\
\hline & Grandes & 17,02 & 8,52 & 12,04 & 8,34 & 69,36 & 79,92 & 1,59 & 0,82 & 2,40 \\
\hline \multirow{2}{*}{ França } & Pequenas & 45,75 & 30,50 & 6,17 & 9,80 & 43,21 & 49,34 & 4,86 & 1,17 & 9,19 \\
\hline & Médias & 29,35 & 24,84 & 8,06 & 11,32 & 60,15 & 56,67 & 2,44 & 2,29 & 4,88 \\
\hline
\end{tabular}




\begin{tabular}{|c|c|c|c|c|c|c|c|c|c|c|}
\hline & Grandes & 11,01 & 9,94 & 19,48 & 25,79 & 62,98 & 61,72 & 6,53 & 0,78 & 1,77 \\
\hline \multirow{3}{*}{ Hungria } & Pequenas & 74,31 & 50,32 & 2,47 & 4,99 & 22,00 & 37,61 & 1,21 & 1,80 & 5,28 \\
\hline & Médias & 67,48 & 27,51 & 12,27 & 3,85 & 14,59 & 63,07 & 5,67 & 1,97 & 3,60 \\
\hline & Grandes & 43,62 & 39,48 & 26,41 & 11,69 & 22,51 & 39,11 & 7,46 & 3,13 & 6,59 \\
\hline \multirow{3}{*}{ Itália } & Pequenas & 65,01 & 48,02 & 5,19 & 4,42 & 26,12 & 31,60 & 3,68 & 2,59 & 13,36 \\
\hline & Médias & 54,08 & 45,53 & 7,08 & 7,08 & 36,29 & 34,15 & 2,54 & 2,06 & 11,18 \\
\hline & Grandes & 29,60 & 25,00 & 15,72 & 11,61 & 48,02 & 48,22 & 6,66 & 1,88 & 13,29 \\
\hline \multirow{3}{*}{ Noruega } & Pequenas & 11,58 & 15,48 & 12,81 & 10,80 & 73,09 & 62,07 & 2,53 & 2,03 & 9,62 \\
\hline & Médias & 16,54 & 17,08 & 16,70 & 11,55 & 65,93 & 59,29 & 0,84 & 3,15 & 8,93 \\
\hline & Grandes & 4,70 & 6,54 & 25,24 & 23,09 & 66,42 & 62,38 & 3,65 & 1,04 & 6,95 \\
\hline \multirow{3}{*}{ Países Baixos } & Pequenas & 51,81 & 21,66 & 22,17 & 15,50 & 19,89 & 49,15 & 6,12 & 7,88 & 5,81 \\
\hline & Médias & 46,43 & 9,65 & 19,58 & 18,13 & 30,62 & 69,12 & 3,36 & 1,04 & 2,05 \\
\hline & Grandes & 13,05 & 5,20 & 22,19 & 29,74 & 63,29 & 61,23 & 1,47 & 2,36 & 1,47 \\
\hline \multirow{3}{*}{ Polônia } & Pequenas & 81,55 & 74,99 & 4,53 & 3,36 & 9,81 & 15,58 & 4,11 & 1,35 & 4,73 \\
\hline & Médias & 91,30 & 57,38 & 1,25 & 5,22 & 6,56 & 31,79 & 0,89 & 1,11 & 4,49 \\
\hline & Grandes & 86,35 & 62,81 & 2,79 & 4,81 & 8,70 & 19,19 & 2,16 & 5,03 & 8,16 \\
\hline \multirow{3}{*}{ Portugal } & Pequenas & 63,50 & 36,94 & 7,51 & 4,94 & 26,99 & 46,12 & 2,00 & 1,13 & 10,87 \\
\hline & Médias & 62,62 & 45,26 & 4,63 & 5,20 & 31,73 & 35,54 & 1,01 & 4,07 & 9,93 \\
\hline & Grandes & 42,55 & 33,84 & 13,26 & 10,77 & 41,37 & 50,35 & 2,83 & 0,93 & 4,11 \\
\hline \multirow{3}{*}{ Reino Unido } & Pequenas & - & 20,15 & - & 10,37 & - & 42,22 & - & 5,65 & 21,61 \\
\hline & Médias & - & 27,79 & - & 15,44 & - & 36,70 & - & 6,65 & 13,41 \\
\hline & Grandes & - & 18,27 & - & 19,92 & - & 54,05 & - & 1,74 & 6,03 \\
\hline \multirow{3}{*}{ Rep. Tcheca } & Pequenas & 62,06 & 57,23 & 17,21 & 5,64 & 19,09 & 26,57 & 1,63 & 2,27 & 8,28 \\
\hline & Médias & 56,73 & 51,86 & 6,09 & 7,20 & 35,24 & 33,59 & 1,93 & 2,09 & 5,26 \\
\hline & Grandes & 60,92 & 44,52 & 17,17 & 24,39 & 19,88 & 23,02 & 2,04 & 3,77 & 4,30 \\
\hline \multirow{3}{*}{ Romênia } & Pequenas & 81,98 & 49,31 & 1,92 & 0,72 & 15,11 & 39,26 & 0,98 & 5,06 & 5,65 \\
\hline & Médias & 80,61 & 56,19 & 5,81 & 0,53 & 10,71 & 39,08 & 2,87 & 0,50 & 3,70 \\
\hline & Grandes & 85,74 & 65,85 & 6,15 & 0 & 7,12 & 24,79 & 0,99 & 0,49 & 8,87 \\
\hline \multirow{3}{*}{ Suécia } & Pequenas & 26,20 & 47,67 & 9,96 & 0 & 54,69 & 52,33 & 9,15 & 0 & 0 \\
\hline & Médias & 33,55 & 27,81 & 8,84 & 0 & 53,34 & 72,19 & 4,27 & 0 & 0 \\
\hline & Grandes & 16,88 & 11,08 & 21,36 & 23,96 & 58,81 & 59,99 & 2,95 & 3,00 & 1,97 \\
\hline \multirow{3}{*}{ Turquia } & Pequenas & - & 62,48 & - & 9,60 & - & 14,25 & - & 5,04 & 8,63 \\
\hline & Médias & - & 87,03 & - & 0,85 & - & 7,29 & - & 0,27 & 4,56 \\
\hline & Grandes & - & 18,89 & - & 8,60 & - & 63,48 & - & 0,91 & 8,12 \\
\hline
\end{tabular}

Fonte: Elaboração própria, a partir de dados da CIS e PINTEC.

Os resultados apresentados na coluna $\mathrm{P} \& \mathrm{D}$ interno (Tabela 3) deixam evidente que essa é a principal forma de gastos em diversos países, principalmente naqueles de renda mais elevada e com sistemas nacionais de inovação mais maduros.

As PEs têm gastos com P\&D interno, proporcionalmente, menores que as de outros portes. Países com melhores resultados para esse porte de empresa são Bélgica, Espanha, Finlândia, França, Noruega e Suécia, com gastos maiores que $40 \%$ em ambos os períodos.

O Brasil tem resultados consideravelmente menores, de $9,20 \%$ e $11,41 \%$ para o primeiro e segundo período, respectivamente. No caso brasileiro, o sistema nacional de inovação menos desenvolvido e as dificuldades enfrentadas pelas PMEs, como a dificuldade de manter mão de obra qualificada e ofertar garantias, por exemplo, impõem barreiras a mais para realizaram desse tipo de atividade e, portanto, menos recursos são destinados ao $\mathrm{P} \& \mathrm{D}$ interno em firmas de menor porte.

Esse resultado é compatível com sugestões de Noteboom (1994) e Rothwell (1989) e também por Acs et al. (1994) que demonstram que as atividades de $P \& D$ interno podem ser prejudicadas em pequenas empresas, que recorrem com mais frequência à aquisição externa, de máquinas, equipamentos e softwares ou conhecimento. A pequena parcela de gastos em P\&D interno pode também ajudar a explicar a elevada participação de inovações de processo nos resultados inovativos no Brasil.

Os resultados mostram que no Brasil tanto as PMEs como as GEs apresentaram melhora no indicador de gastos em atividades de $\mathrm{P} \& \mathrm{D}$ interno do primeiro para o segundo período, ainda que permaneçam em patamares inferiores a de outros países como Reino Unido, França, Espanha e Alemanha. Esse fenômeno pode ser explicado por um conjunto de políticas públicas adotadas nos períodos recentes para incentivar a inovação. Organizações e legislações criadas no Brasil, como a Lei do Bem, tiveram relevante impacto no financiamento e viabilidade de projetos inovativos, além de programas criados 
especificamente para PMEs, alguns promovidos pela Financiadora de Estudos e Projetos (FINEP). Avellar e Botelho (2015) sugerem que as iniciativas públicas tiveram relevante impacto positivo nos resultados de inovação, e nos gastos em P\&D interno, principalmente em PMEs.

Alguns países como Áustria, Bélgica, Espanha, Finlândia, França, Noruega e Suécia apresentam parcelas elevadas em ambos os períodos para grandes e médias empresas. Também é possível notar que esse tipo de gasto teve crescimento significativo do primeiro para o segundo período nas médias empresas, assim como nas pequenas, em praticamente todos os países analisados.

Assim como para máquinas, equipamentos e softwares, as GEs apresentam, proporcionalmente, gastos maiores que as PMEs em P\&D interno. Os resultados ainda permitem concluir que os gastos com P\&D interno são o principal tipo de dispêndio para a maior parte dos países de renda mais elevada e com estruturas industriais mais complexas do Bloco Europeu, em ambos os períodos analisados. As GEs brasileiras também gastam mais que as PMEs nesse tipo de atividade inovativa, ainda que em nível menor que a dos países citados anteriormente. O nível de gastos das GEs brasileiras em atividades internas de P\&D é mais próximo aos de Espanha e Hungria.

As informações sobre conhecimento externo referem-se à parcela de gastos relativos às patentes, licenças, marcas registradas, serviços de consultoria dentre outros, o que difere do conceito de aquisição de P\&D externo. Os dados demonstram que poucos recursos são destinados a esse tipo de gasto inovativo. Não há um padrão que diferencie as empresas por porte. No Brasil as pequenas empresas tiveram um aumento considerável na proporção dos gastos com aquisição de conhecimento externo no segundo período em relação ao primeiro, ultrapassando os $10 \%$ dos gastos em atividades inovativas. Essa evolução também é registrada nos Países Baixos, Romênia e República Tcheca. Todos os demais países apresentaram queda no indicador para empresas de pequeno porte.

As médias empresas brasileiras registraram um resultado de 2,48\% e 1,67\% para o primeiro e segundo período, respectivamente, o que indica uma pequena variação negativa, assim como registrado na Alemanha, Espanha, França, Finlândia. Para GEs, os gastos em aquisição de conhecimento externo foram próximos de 3\% para o Brasil em ambos os períodos. Para os demais países, como já dito, o perfil deste tipo de gasto não se altera muito do observado nos demais portes de empresa, à exceção da Espanha onde, em ambos os períodos, o indicador mostra que estes gastos representam uma parcela significativa nas GEs, de $10,48 \%$ e $6,97 \%$ no primeiro e no segundo período, respectivamente.

A última coluna da Tabela 3, intitulada Outros, corresponde às outras atividades inovativas que podem ser compreendidas como atividades “não P\&D”, mas que resultam em inovação, podendo fortalecer as capacitações e habilidades que permitem o desenvolvimento de inovações ou a ampliar a capacidade de desenvolver uma adoção bem sucedida. É necessário destacar que a mudança metodológica na CIS apenas permitiu a análise comparativa com o Brasil no segundo período. A PINTEC realiza uma divisão considerando gastos com treinamento, com projetos industriais e introdução das inovações no mercado, que para efeito de comparação tiveram seus valores somados, resultando em "outros gastos em atividades inovativas".

Percebe-se que esse tipo de gasto é mais importante para firmas menores que para as maiores. Em países como Alemanha, Itália, Reino Unido e Brasil esses gastos se situam entre 13,36\% a 27,07\%. Na Alemanha, as empresas com 50 a 249 funcionários, têm cerca de $23 \%$ de seus gastos em outras atividades inovativas. As médias empresas brasileiras também apresentam gastos em outras atividades inovativas maiores que as congêneres dos demais países, representando $12,52 \%$ do total de gastos em atividades inovativas, e maior que a média de $6,68 \%$.

Grandes empresas apresentam, em média, uma participação menor de outros gastos em atividades inovativas se comparadas com as menores. Na Alemanha o indicador é de 17,23\%, Itália de 12,29\% e Brasil de $12,18 \%$. Para a maior parte das GEs de outros países esse tipo de gasto representa menos de 5\% do total de gastos inovativos.

Em suma, a partir os resultados da Tabela 3 é possível concluir que os gastos mais representativos em atividades inovativas são os de P\&D interno e aquisição de máquinas, equipamento e softwares. Esses dois tipos de dispêndio concentram a maior parte dos gastos em qualquer um dos recortes por tamanho.

Com isso pode-se inferir que para PMEs a aquisição de pacotes tecnológicos, ou adaptação de máquinas, equipamentos e softwares são o principal destino de recursos para estabelecimento de atividades 
inovativas. Esse padrão é observado com mais intensidade no Brasil e em países do Leste Europeu, sendo que outros países como Alemanha, França, Espanha e Suécia, destinam a maior parte de seus recursos para P\&D interno.

Isso pode demonstrar uma diferença em relação ao foco das atividades inovativas, uma vez que P\&D interno demanda o desenvolvimento sistêmico de atividades inovativas, enquanto a aquisição de máquinas, equipamentos e software pode ser efetivada utilizando recursos externos à firma, apresentandose fundamentalmente como processos de modernização tecnológica e induzindo à inovações que possam não ser novas para o mercado, mas apenas para a firma. Além disso, a aquisição de máquinas, equipamentos e softwares está diretamente ligada às inovações de processo, o que pode explicar o desempenho focado em inovações de processo no Brasil, fundamentalmente em PEs.

\subsection{Cooperação}

Há uma intensa discussão na literatura sobre a importância da cooperação nos processos inovativos e quais são os parceiros mais frequentes. Nesse sentido, seguindo as orientações do Manual de Oslo, ambas as pesquisas CIS e PINTEC, elaboram em seus questionários uma separação por parceiros com quem as empresas realizam inovações. São esses: Empresas do mesmo grupo, Empresas do mesmo setor ou concorrentes, Fornecedores, Consumidores, Universidades, Consultores e Governo ${ }^{5}$.

A Tabela 4 apresenta a taxa de cooperação propriamente dita. Essa taxa é calculada como a parcela das empresas inovadoras que estão envolvidas em algum tipo de cooperação durante o período da pesquisa. $\mathrm{O}$ indicador mostra que apenas $10,38 \%$ das empresas brasileiras que inovaram no período 1 cooperaram, enquanto para o período 2 esse indicador foi de 16,74\%. Ambos os valores são próximos aos resultados da Itália, Alemanha e Espanha, mas inferiores à taxa média de cooperação. Países como França, Bélgica, Dinamarca e Finlândia apresentam taxas significativamente maiores de cooperação.

Os resultados também sugerem que PEs brasileiras cooperam menos que médias empresas e muito menos que GEs. Esse padrão também é verificado nos outros países. Quando analisados os resultados para as médias dos dados, as PEs cooperam menos que as de outros portes.

Esse resultado reforça os argumentos que explicitam as dificuldades de se realizar cooperação para inovação em PEs. Rogers (2004) aponta que a falta de recursos e de mão de obra especializada nas PMEs podem impedir ou dificultar o estabelecimento de cooperação. Trabalhos de Chun e Mun (2012) e Muscio (2007) sugerem que a capacidade de absorção de informações pode ser determinante para o sucesso ao realizar cooperação, uma vez que a cooperação pode ter por alvo a captação de spillovers, e esta capacidade é frequentemente mais deficiente em PMEs.

Também é possível identificar que países com maior participação de empresas desenvolvendo atividades de $\mathrm{P} \& \mathrm{D}$ interno, ou com maior parcela de seus gastos inovativos em $\mathrm{P} \& \mathrm{D}$ interno, como apresentado anteriormente, estão entre os que tem maior taxa de cooperação, assim como sugere Acs et al. (1994), Chun e Mun (2012) e Muscio (2007). São exemplos desse grupo, Finlândia, França, Bélgica, Dinamarca e Países Baixos.

Da mesma forma, países cujas PMEs que, relativamente, gastam menos com atividades de P\&D interno que as GEs, têm menor taxa de cooperação. Como sugerido por Muscio (2007) empresas que já tenham desenvolvido P\&D interno podem ter vantagens para inovar com cooperação. Acs et al. (1994), Noteboom (1994) e Rothwell (1989) também sugerem que PEs têm maior dificuldade em estabelecer atividades internas de P\&D, Isso também ajuda a explicar as taxas de cooperação menores em PMEs que em GEs.

De modo geral, não há variação muito significativa de um período para o outro. Suécia, Dinamarca e Bélgica têm taxas de cooperação mais elevadas para PEs quando comparadas com as congêneres brasileiras. Ainda assim, as taxas de cooperação para empresas dos primeiros países citados são sempre menores que as taxas das empresas de grande porte. Para a maioria dos países analisados, a taxa de cooperação é maior para empresas de 50 a 249 funcionários do que para as pequenas. O Brasil tem taxas

\footnotetext{
${ }^{5}$ Para cada um desses quesitos foi elaborada uma tabela específica para o trabalho que originou este artigo. Por razões de espaço não serão apresentadas. Os dados sistematizados serão utilizados para qualificar os resultados gerais de cooperação expostos na Tabela 4.
} 
de cooperação de $12,70 \%$ e $21,36 \%$ nesses segmentos, maiores que as de PEs, mas ainda assim menores que de outros países como República Tcheca, Bélgica, Reino Unido e Dinamarca.

Tabela 4 - Taxa de cooperação para inovação nos períodos um e dois para Brasil e países europeus, em porcentagem

\begin{tabular}{|c|c|c|c|c|c|c|c|c|}
\hline \multirow[t]{2}{*}{ País } & \multicolumn{2}{|c|}{ Total de empresas } & \multicolumn{2}{|c|}{$\begin{array}{c}\text { Empresas com } 10 \text { a } 49 \\
\text { funcionários }\end{array}$} & \multicolumn{2}{|c|}{$\begin{array}{c}\text { Empresas com } 50 \text { a } 249 \\
\text { funcionários }\end{array}$} & \multicolumn{2}{|c|}{$\begin{array}{c}\text { Empresas com } 250 \text { ou mais } \\
\text { funcionários }\end{array}$} \\
\hline & P1 & $\mathrm{P} 2$ & P1 & P2 & P1 & P2 & P1 & $\mathrm{P} 2$ \\
\hline Alemanha & 16,49 & 19,50 & 13,13 & 14,78 & 20,67 & 26,18 & 42,42 & 46,93 \\
\hline Áustria & 29,58 & 31,04 & 23,21 & 25,88 & 37,78 & 37,31 & 63,30 & 59,51 \\
\hline Bélgica & 40,27 & 43,74 & 36,63 & 38,27 & 46,66 & 53,94 & 66,36 & 68,48 \\
\hline Brasil & 10,38 & 16,74 & 8,63 & 14,03 & 12,70 & 21,36 & 27,33 & 40,18 \\
\hline Dinamarca & 46,53 & 30,99 & 42,06 & 25,25 & 52,81 & 38,50 & 69,54 & 62,36 \\
\hline Espanha & 13,70 & 20,26 & 10,27 & 15,00 & 21,95 & 30,75 & 41,17 & 49,07 \\
\hline Finlândia & 33,00 & 30,60 & 27,29 & 25,01 & 39,00 & 36,49 & 67,67 & 66,98 \\
\hline França & 29,62 & 23,91 & 25,12 & 18,92 & 36,18 & 32,38 & 54,42 & 51,70 \\
\hline Hungria & 29,64 & 20,76 & 22,25 & 14,23 & 37,20 & 29,46 & 60,58 & 51,26 \\
\hline Itália & 12,21 & 9,42 & 9,65 & 7,84 & 20,61 & 13,06 & 40,95 & 34,61 \\
\hline Noruega & 28,32 & 19,66 & 25,26 & 15,13 & 32,64 & 27,65 & 48,03 & 48,84 \\
\hline Países Baixos & 31,33 & 29,09 & 26,51 & 27,28 & 39,67 & 32,14 & 55,84 & 43,45 \\
\hline Polônia & 27,83 & 21,86 & 18,84 & 11,97 & 35,64 & 29,50 & 58,18 & 50,95 \\
\hline Portugal & 24,60 & 14,28 & 20,77 & 9,93 & 33,45 & 23,17 & 58,74 & 54,64 \\
\hline Reino Unido & 55,44 & 45,10 & 54,27 & 43,12 & 59,43 & 51,06 & 56,34 & 55,52 \\
\hline Rep. Tcheca & 23,08 & 30,23 & 16,59 & 22,02 & 32,78 & 42,96 & 54,21 & 55,18 \\
\hline Romênia & 8,15 & 7,37 & 6,19 & 5,75 & 9,59 & 6,93 & 20,47 & 22,55 \\
\hline Suécia & 33,20 & 24,35 & 30,01 & 21,53 & 36,64 & 29,24 & 59,19 & 47,35 \\
\hline Turquia & - & 9,57 & - & 8,52 & - & 10,25 & - & 26,37 \\
\hline Média & 26,49 & 23,29 & 22,51 & 18,94 & 32,20 & 30,01 & 50,46 & 47,78 \\
\hline Desvio Padrão & 0,113 & 0,097 & 0,109 & 0,090 & 0,133 & 0,125 & 0,158 & 0,135 \\
\hline
\end{tabular}

Fonte: Elaboração própria, a partir de dados da CIS e PINTEC.

De modo geral, PMEs apresentam taxas de cooperação menores que as GEs. No Brasil 27,33\% e $40,18 \%$, no primeiro e segundo período respectivamente, das GEs que inovam realizam cooperação, mostrando que houve grande variação de um período para outro. A taxa brasileira é razoavelmente próxima da taxa da Itália, porém menor que as da Bélgica, Reino Unido, Dinamarca e Portugal, com indicadores superiores a 50\%. Também é perceptível que há aumento da taxa de cooperação no Brasil do primeiro para o segundo períodos em todos os portes analisados.

Em relação aos parceiros da cooperação, identificou-se que:

- Para o total de empresas no Brasil, a cooperação com outras empresas do mesmo grupo, em ambos os períodos, tem participações menores que de todos os outros países;

- Ao realizar a análise quanto ao tamanho das empresas percebe-se que PMEs cooperam menos com empresas do mesmo grupo que GEs, o que é esperado pois quanto menor a empresa menor é a probabilidade de fazer parte de um grupo;

- A cooperação com fornecedores de equipamentos, componentes e softwares é mais frequente que a cooperação com empresas do mesmo grupo, e de modo geral se percebem diferenças relevantes em relação ao tamanho das empresas nesse tipo de cooperação;

- Aproximadamente $64 \%$ e $71 \%$ do total das empresas brasileiras que cooperaram, o fizeram com fornecedores. As GEs são as que mais cooperam com fornecedores, tanto no primeiro como no segundo período, embora haja pouca diferença entre os resultados dos indicadores para as PMEs;

- A cooperação com fornecedores é muito frequente em todos os países e não há um padrão definido capaz de separar os países com sistemas de inovação mais maduros daqueles menos maduros;

- Sobre a cooperação com clientes e consumidores, os resultados indicam que para o Brasil não há grande diferença entre o porte das empresas, ainda que GEs cooperem mais que PMEs. A maior diferença para o Brasil seria em relação aos períodos, onde no segundo período analisado há substancial crescimento na taxa de cooperação com clientes para todos os portes de empresas;

- A cooperação com clientes e consumidores também não apresenta um padrão definido capaz de separar os países com sistemas de inovação mais maduros daqueles menos maduros, embora em menor grau que o tipo anterior;

- Para a cooperação com concorrentes e empresas do mesmo setor, os resultados mostram que para o total de empresas, no Brasil, esse tipo de cooperação é menos frequente do que com fornecedores ou clientes; 
- Percebe-se que GEs cooperam mais com concorrentes que as PMEs, muito embora a maior diferença seja na comparação entre os períodos, sendo que no segundo a taxa é maior;

- Com exceção de Finlândia, a maior parte das PMEs dos demais países apresentam taxas menores que $50 \%$, indicando que cooperar com concorrentes não é tão frequente entre as empresas que cooperam e também não há um padrão que diferencie os países segundo seus sistemas de inovação.

- Os resultados mostram que, no total de empresas, há maior parcela de firmas que cooperaram com consultorias do que com concorrentes, para o Brasil e para maior parte dos outros países, como Bélgica, Dinamarca, França, Itália e Noruega;

- Para as PEs brasileiras, a taxa de cooperação com consultorias, laboratórios comerciais e institutos privados é menor que para a maior parte dos outros países. As médias empresas brasileiras apresentam taxas de cooperação menores que as verificadas em outros países, e no período um, menor que as de PEs. As médias empresas do Brasil têm taxa de cooperação com consultorias maior que as da Alemanha, Áustria e Espanha, embora menor que dos demais países;

- Os resultados da média geral dos dados mostram que a cooperação com Universidades é mais frequente que com concorrentes. Para o total de empresas, o Brasil apresenta taxas de 31,10\% e $29,33 \%$ no primeiro e segundo períodos, respectivamente. Esse resultado é próximo ao observado na França e Romênia, mas inferior à maior parte dos demais países europeus;

- As PMEs cooperam menos com Universidades do que GEs, e no Brasil tal cooperação é mais frequente do que cooperação com concorrentes. Entretanto, assim como na cooperação com empresas do mesmo grupo, esse tipo de cooperação é menor no Brasil do que nos outros países. Mais uma vez não há um padrão que separe de forma clara os países europeus, ainda que a maior parte dos países de renda menor tenham taxas de cooperação menores.

\subsection{Apoio do Governo}

Com vistas a mensurar o apoio do governo, tanto a CIS como a PINTEC questionam sobre a participação de financiamento público para atividades inovativas. $\mathrm{O}$ indicador considera o número de empresas inovadoras que receberam financiamento público divido pela quantidade de empresas inovadoras (Tabela 5).

No Brasil, percebe-se que há menor parcela de PMEs recebendo financiamento público que GEs, ou seja, o financiamento público tem maior penetração entre as GEs. O indicador mostra que PMEs tiveram melhora no segundo período em relação ao primeiro, mesmo assim o indicador é menor que o das GEs. De certa forma, esse padrão também é acompanhado pelos demais países analisados.

Aproximadamente $33 \%$ das pequenas empresas do Brasil receberam financiamento público no segundo período, taxa que só não é maior que a dos Países Baixos, de 35,91\%. As médias empresas, no Brasil, não apresentam grande diferença com as pequenas, dado que cerca de $23 \%$ e $33 \%$ das primeiras receberam financiamento público no primeiro e segundo períodos, respectivamente. Nesse sentido, apenas Áustria, Países Baixos e França têm indicadores maiores que os do Brasil.

Tabela 5 - Empresas que implementaram inovações e receberam financiamento público no Brasil e países europeus, em porcentagem

\begin{tabular}{|c|c|c|c|c|c|c|c|c|}
\hline \multirow[t]{2}{*}{ País } & \multicolumn{2}{|c|}{ Total de empresas } & \multicolumn{2}{|c|}{$\begin{array}{l}\text { Empresas com } 10 \text { a } 49 \\
\text { funcionários }\end{array}$} & \multicolumn{2}{|c|}{$\begin{array}{c}\text { Empresas com } 50 \text { a } 249 \\
\text { funcionários }\end{array}$} & \multicolumn{2}{|c|}{$\begin{array}{l}\text { Empresas com } 250 \text { ou mais } \\
\text { funcionários }\end{array}$} \\
\hline & P1 & $\mathrm{P} 2$ & P1 & P2 & P1 & $\mathrm{P} 2$ & P1 & P2 \\
\hline Alemanha & 15,32 & 19,47 & 13,79 & 17,54 & 17,50 & 22,68 & 26,02 & 29,10 \\
\hline Áustria & 30,53 & 28,62 & 24,66 & 21,93 & 40,49 & 38,53 & 53,98 & 59,51 \\
\hline Bélgica & 18,36 & 22,06 & 16,77 & 19,02 & 19,22 & 25,15 & 37,79 & 45,05 \\
\hline Brasil & 22,33 & 34,16 & 21,43 & 33,36 & 23,25 & $\mathbf{3 3 , 5 2}$ & 31,84 & 48,47 \\
\hline Espanha & 19,30 & 19,35 & 16,67 & 15,92 & 25,63 & 26,45 & 40,33 & 37,10 \\
\hline Finlândia & 31,14 & 29,63 & 27,69 & 26,93 & 34,42 & 29,85 & 53,47 & 55,45 \\
\hline França & 11,63 & 33,87 & 11,01 & 28,30 & 12,21 & 44,46 & 16,04 & 61,21 \\
\hline Hungria & 19,71 & 23,04 & 19,41 & 21,39 & 19,20 & 26,14 & 22,94 & 28,14 \\
\hline Itália & 23,63 & 16,28 & 20,81 & 14,70 & 35,19 & 21,52 & 43,02 & 33,47 \\
\hline Países Baixos & 21,66 & 40,61 & 18,31 & 35,91 & 28,71 & 52,25 & 34,16 & 57,09 \\
\hline Polônia & 12,56 & 16,17 & 8,85 & 12,11 & 18,52 & 21,76 & 17,05 & 21,40 \\
\hline Portugal & 11,11 & 21,51 & 7,95 & 17,62 & 19,53 & 30,70 & 33,33 & 51,99 \\
\hline Rep. Tcheca & 11,97 & 20,09 & 7,54 & 14,04 & 19,95 & 30,56 & 28,87 & 35,79 \\
\hline Romênia & 5,76 & 5,29 & 4,38 & 4,06 & 8,21 & 6,71 & 10,11 & 11,69 \\
\hline Suécia & - & 10,52 & - & 10,35 & - & 8,58 & - & 20,08 \\
\hline
\end{tabular}




\begin{tabular}{lccccccc} 
Turquia & - & 13,35 & - & 12,00 & - & 16,69 & 24,58 \\
\hline Média & 16,62 & 19,94 & 14,00 & 17,06 & 21,24 & 25,20 & 33,81 \\
Desvio Padrão & 0,070 & 0,083 & 0,068 & 0,078 & 0,085 & 0,101 \\
\hline
\end{tabular}

Fonte: Elaboração própria, a partir de dados da CIS e PINTEC.

Enquanto a taxa para GEs no Brasil chega a 48,47\% no segundo período, em outros países, como Finlândia, Países Baixos e França esse valor ultrapassa os 50\%. Portugal apresenta um desempenho próximo ao brasileiro, e Alemanha taxas maiores. Esses resultados indicam que, apesar de alguns esforços recentes, as PMEs ainda não conseguem apoio do governo por meio de financiamento público da mesma forma que GEs. Isso ocorre no Brasil, mas com ainda mais intensidade em Portugal, Espanha e França. É importante destacar que o Brasil apresenta resultados acima da média, o que mostra o papel de destaque que o governo tem para o financiamento da inovação no País.

Matos e Arroio (2011) destacam que houve, no período analisado, diversas políticas de apoio ao financiamento de pequenas empresas, e de fomento à inovação. Programas com o Fundo de Financiamento para Aquisição de Máquinas e Equipamentos (FINAME), apoio de bancos estatais como o BNDES com linhas de crédito dirigidas a PEs, e suporte da FINEP, criação de Fundos Setoriais, além de projetos de subvenção econômica foram fundamentais para o financiamento de PEs, e de projetos inovativos. Parte desses projetos esteve ligada a políticas industriais mais amplas como a Política Industrial, Tecnológica e de Comércio Exterior (PITCE) e o Plano de Desenvolvimento Produtivo (PDP).

Conforme destacado anteriormente, a maior parte dos trabalhos apresentados demonstram que há efeito additionality, ou de complementação entre o financiamento público e o privado para inovação. $\mathrm{O}$ apoio de políticas públicas de financiamento, ou crédito fiscal, pode ser de fundamental importância para que PMEs realizem investimentos em P\&D e em outras atividades inovativas, e se tornem aptas a desenvolver qualquer tipo de inovação.

\section{Considerações finais}

O presente trabalho buscou contribuir para a literatura de inovação em empresas de pequeno porte, apresentando particularidades enfrentadas pelas PMEs no processo inovativo, a partir de uma análise comparativa entre resultados das pesquisas de inovação do Brasil e países da União Europeia.

Os resultados apontam diferenças nas atividades inovativas segundo o porte de empresas que, em geral, confirmam proposições da literatura de referência. Vale dizer, as taxas de inovação crescem segundo o porte de empresas; as atividades inovativas das empresas de pequeno porte concentram-se em gastos com a aquisição de máquinas e equipamentos, especialmente nos países menos desenvolvidos; as atividades cooperativas são empreendidas em maior proporção por empresas maiores e estas tendem a ter um leque maior de agentes com os quais cooperam; e, ainda, as empresas menores encontram maiores dificuldades para financiar suas atividades inovativas, considerando-se o acesso ao apoio do governo.

Também se identifica, nos dados sistematizados no presente trabalho, que as empresas brasileiras, especialmente as de pequeno porte, possuem resultados que se comparam, em geral, aos obtidos por países que possuem sistemas de inovação menos desenvolvidos, como Espanha e Portugal e países do Leste Europeu.

Entretanto, apesar de os dados confirmarem fatos estilizados pela literatura de referência sobre atividades inovativas de empresas de pequeno porte, em nível geral e em particular para as brasileiras, a diversidade encontrada é significativa. Sobre essa diversidade, destaque-se que:

- Taxas de inovação variam significativamente entre países, apesar de mostrar-se crescente segundo o porte. A comparação entre países mostra que a taxa de inovação das PEs pode ser inferior às encontradas para as grandes empresas (Alemanha e Brasil são exemplos) e alguns países exibem taxas de inovação que diferenciam-se pouco segundo o porte (Reino Unido é o principal exemplo);

- Gastos em P\&D, em geral, também crescem segundo o porte. Entretanto, há países em que os gastos são mais próximos entre os diferentes porte (Alemanha e Finlândia, por exemplo) e outros em que os maiores gastos são efetuados pelas empresas de menor porte (Espanha e Finlândia são exemplos);

- Para a maior parte dos países, observou-se que as PMEs têm, em geral, menor diversidade na forma com que realizam os gastos com atividades inovativas, quando comparadas com GEs, concentrando seus gastos, principalmente, em aquisição de máquinas e equipamentos. Para essa atividade a 
diferença entre as pequenas e grandes empresas não é tão grande. Tanto no Brasil como em países do Leste Europeu esse tipo de atividade inovativa é a mais utilizada pela maior parte das empresas inovadoras;

- A taxa de cooperação também é maior para GEs do que para as de menor porte, tanto no Brasil como na maioria dos demais países. Para o conjunto de países, à exceção de Brasil, Alemanha, Áustria, Bélgica e Espanha, a taxa de cooperação é menor no segundo período que no primeiro. Essa mudança positiva para o Brasil é fruto, muito provavelmente, de um conjunto de políticas públicas de incentivo à inovação, implementadas no período que compreende as duas versões analisadas da PINTEC (MATOS e ARROIO, 2011; AVELLAR e BOTELHO, 2014);

- Sobre o apoio do governo, o resultado encontrado para as PMEs brasileiras é superior à maioria dos demais países, além de apresentar significativo aumento do primeiro para o segundo período. Isso pode ser resultado de políticas públicas adotadas no período das pesquisas e que visavam o financiamento de inovações, sendo vários desses programas com foco em PEs. Desse modo, o Brasil tem taxa de apoio do governo próxima a de outros países com sistemas de inovação mais desenvolvidos.

- O Brasil apresenta pequeno dinamismo inovativo, expresso pela taxa de inovação menor que a maioria dos demais países, ainda que o País tenha considerável esforço inovativo, principalmente em PMEs. Tanto no primeiro como no segundo período, as PMEs brasileiras inovam mais frequentemente em processo do que em produto, cooperam menos, apesar do aumento do apoio do governo na forma de financiamento, e concentram mais seus gastos inovativos em poucas atividades, além de focar em poucos parceiros quando exercem cooperação.

As diferenças identificadas nos dados que compõem este trabalho apontam para a diversidade que cerca as atividades inovativas das empresas, segundo a referência do enfoque de sistemas nacionais de inovação. Relacionar de forma mais estreita as diferenças às estruturas dos diferentes sistemas de inovação é um passo posterior da pesquisa, entendendo-se que essa é uma lacuna importante nas pesquisas de inovação, para a qual entende-se que o presente trabalho apresenta uma contribuição inicial.

\section{Referências bibliográficas}

ACS, Zoltan J.; AUDRETSCH, David B. Innovation and small firms. Mit Press, 1990.

ACS, Zoltan J. et al. R \& D spillovers and recipient firm size. The Review of Economics and Statistics, p. 336-340, 1994.

AUDRETSCH, D. B. Standing on the shoulders of midgets: The US Small Business Innovation Research program (SBIR). Small Business Economics, v. 20, n. 2, p. 129-135, 2003.

AVELlAR, A. P. M.; BOTELHO, M. R. A. Políticas de apoio à inovação em pequenas empresas: evidências sobre a experiência brasileira recente. Economia e Sociedade, v. 24 (2), p. 379-417, 2015.

AVELlAR, A. P. M.; BOTELHO, M. R. A. Impacto das Políticas de Inovação nas Pequenas, Médias e Grandes Empresas Brasileiras. Anais do XLII Encontro Nacional de Economia. Associação Nacional dos Centros de Pós-graduação em Economia, 2016.

BRANCATI, E. Innovation financing and the role of relationship lending for SMEs. Small Business Economics, v. 44 (2), p. 449-473, 2015.

CECI, F.; IUBATTI, D. Personal relationships and innovation diffusion in SME networks: A content analysis approach. Research Policy, v. 41 (3), p. 565-579, 2012.

CHUN, H.; MUN, S. Determinants of R\&D cooperation in small and medium-sized enterprises. Small Business Economics, v. 39 (2), p. 419-436, 2012.

COHEN, W. M.; LEVINTHAL, D. A. Absorptive capacity: A new perspective on learning and innovation. Administrative science quarterly, p. 128-152, 1990.

CZARNITZKI, D.; HOTTENROTT, H. R\&D investment and financing constraints of small and mediumsized firms. Small Business Economics, v. 36 (1), p. 65-83, 2011.

EUROSTAT. Community Innovation Survey. Banco de Dados. Disponível em:

<http://ec.europa.eu/eurostat/web/science-technology-innovation/data/database>. Acesso em: 15 de julho de 2016. 
FILIPPETTI, A.; ARCHIBUGI, D. Innovation in times of crisis: National Systems of Innovation, structure, and demand. Research Policy, Vol. 40, pp. 179-92, 2011.

LEE, N.; SAMEEN, H.; COWLING, M.. Access to finance for innovative SMEs since the financial crisis. Research policy, v. 44 (2), p. 370-380, 2015.

LUNDVALL, B. A. National innovation system: towards a theory of innovation and interactive learning. Pinter, London, 1992.

MANCUSI, M. L.; VEZZULLI, A. R\&D and credit rationing in SMEs. Economic Inquiry, v. 52 (3), p. 1153-1172, 2014.

MANUAL DE OSLO: Diretrizes para coleta e interpretação de dados sobre inovação. Versão traduzida por FINEP. Brasil, 2005.

MARTIN, S.; SCOTT, J. T. The nature of innovation market failure and the design of public support for private innovation. Research policy, v. 29 (4), p. 437-447, 2000.

MATOS, M. P.; ARROIO, A. Políticas de apoio a micro e pequenas empresas no Brasil: avanços no período recente e perspectivas futuras. 2011.

MUSCIO, A. The impact of absorptive capacity on SME's collaboration. Economics of Innovation and New Technology, v. 16, n. 8, p. 653-668, 2007.

NOOTEBOOM, B. Innovation and diffusion in small firms: theory and evidence. Small Business Economics, v. 6 (5), p. 327-347, 1994.

PINTEC. Pesquisa de Inovação Tecnológica - 2008. Rio de Janeiro, IBGE, 2010. Disponível em: < http://www.pintec.ibge.gov.br/downloads/PUBLICACAO/Publicacao\%20PINTEC\%202008.pdf> .

PINTEC. Pesquisa de Inovação Tecnológica - 2011. Rio de Janeiro, IBGE, 2013. Disponível em: <http://www.pintec.ibge.gov.br/downloads/pintec2011\%20publicacao\%20completa.pdf> .

REVEST, V.; SAPIO, A. Financing technology-based small firms in Europe: what do we know?. Small Business Economics, v. 39 (1), p. 179-205, 2012.

ROGERS, M. Networks, firm size and innovation. Small business economics, v. 22 (2), p. 141-153, 2004. ROTHWELL, R. Small firms, innovation and industrial change. Small Business Economics, v. 1(1), p. 51-64, 1989.

UYARRA, E. et al. Barriers to innovation through public procurement: A supplier perspective. Technovation, v. 34 (10), p. 631-645, 2014.

WINKER, P. Causes and effects of financing constraints at the firm level. Small Business Economics, v. 12 (2), p. 169-181, 1999.f 